\title{
Antiproliferative, anticholinesterase and anti-phosphodiesterase inhibitory properties of the DCM sub-extract of Uvaria alba: Evidence from in silico target fishing and in vitro testing
}

Mark Tristan J. Quimque ${ }^{\mathrm{a}, \mathrm{b}, \mathrm{e} \dagger}$, Kin Israel R. Notarte ${ }^{\mathrm{a}, \mathrm{c} \dagger}$, Arianne G. Letada ${ }^{\mathrm{a}, \mathrm{b} \dagger}$, Rey Arturo T. Fernandez ${ }^{\mathrm{a}}$, Delfin Yñigo H. Pilapil IV ${ }^{\mathrm{a}, \mathrm{d}}$, Kirstin Rhys S. Pueblos ${ }^{\mathrm{a}, \mathrm{b}, \mathrm{e}}$, Jay Carl M. Agbay ${ }^{\mathrm{e}, \mathrm{f}}$, HansMartin Dahse ${ }^{\mathrm{g}}$, Arlette Wenzel-Storjohann ${ }^{\mathrm{h}}$, Deniz Tasdemir ${ }^{\mathrm{h}, \mathrm{i}}$, Abbas Khan ${ }^{\mathrm{j}}$, Dong-Qing Wei ${ }^{\mathrm{j}, \mathrm{k}}$ and Allan Patrick G. Macabeo, ${ }^{\mathrm{a}, *}$

${ }^{a}$ Laboratory of Organic Reactivity, Discovery and Synthesis, Research Center for Natural and Applied Sciences, University of Santo Tomas, 1015 España, Manila, Philippines

${ }^{b}$ The Graduate School, University of Santo Tomas, 1015 España, Manila, Philippines

${ }^{c}$ Faculty of Medicine and Surgery, University of Santo Tomas, 1015 España, Manila, Philippines

${ }^{\mathrm{d}}$ Department of Biological Sciences, College of Science, University of Santo Tomas, 1015 España, Manila, Philippines

${ }^{\text {e}}$ Department of Chemistry, College of Science and Mathematics, Mindanao State UniversityIligan Institute of Technology, Tibanga, 9200 Iligan City, Philippines fPhilippine Science High School - Central Mindanao Campus, 9217 Balo-i, Lanao del Norte, Philippines ${ }^{\mathrm{g}}$ Leibniz-Institute for Natural Product Research and Infection Biology, Hans-Knöll-Institute (HKI), D07745 Jena, Germany

${ }^{\text {h} G E O M A R ~ C e n t r e ~ f o r ~ M a r i n e ~ B i o t e c h n o l o g y ~(G E O M A R-B i o t e c h), ~ R e s e a r c h ~ U n i t ~ M a r i n e ~ N a t u r a l ~}$ Products Chemistry, GEOMAR Helmholtz Centre for Ocean Research Kiel, Am Kiel-Kanal 44, Kiel 24106, Germany

${ }^{\mathrm{i}}$ Faculty of Mathematics and Natural Sciences, Kiel University, Christian-Albrechts-Platz 4, 24118 Kiel, Germany

${ }^{j}$ Department of Bioinformatics and Biostatistics, State Key Laboratory of Microbial Metabolism, Shanghai Jiao Tong University, 800 Dongchuan Road Shanghai, Minhang District, China, 200240

${ }^{k}$ Peng Cheng Laboratory, Vanke Cloud City Phase I Building 8, Xili Street, Nashan District, Shenzhen, Guangdong, 518055, P.R. China

$\dagger$ These authors contributed equally to this work.

*Corresponding author: agmacabeo@ust.edu.ph / allanpatrick_m@yahoo.com 


\begin{abstract}
Aims: To evaluate the in vitro antiproliferative, anticholinesterase and anti-phosphodiesterase activities of the sub-extracts of Uvaria alba (family Annonaceae) and explore putative binding mechanisms of its chemical constituents in silico.

Main methods: $U$. alba sub-extracts, obtained by solvent-solvent partition, were subjected to antiproliferative and cytotoxicity screening against chronic myelogenous leukemia (K-562) and human cervical cancer (HeLa) cells, respectively. Inhibitory assays against acetylcholinesterase (AChE) and phosphodiesterase (PDE4 B2) enzymes were also performed. The dichloromethane sub-extract (UaD) was chemically profiled using LC-HR-ESIMS-QToF to identify secondary metabolites 1-18. Molecular docking and molecular dynamics simulations were performed to determine the affinity of the putatively annotated metabolites against PDE4 B2B, AChE, ubiquitin specific peptidase 14 (USP14), and Kelch-like ECH-associated protein 1 (Keap1). In addition, DFT calculations were also performed to demonstrate Michael addition reaction between electrophilic cytotoxic metabolites and Cys 151 of the Keap1-BTB domain.

Key findings: UaD showed antiproliferative and cytostatic activities against K-562 and HeLa, respectively, and inhibitory activities against AChE and PDE4 B2. Meanwhile, its polyphenolic constituents 3-(3,4-dihydroxybenzyl)-3',4',6-trihydroxy-2,4-dimethoxychalcone (8) and grandifloracin (15) showed favorable binding to AChE and Keap1-BTB domain, respectively. The most electrophilic and kinetically stable grandifloracin (15), favorably formed a beta-addition adduct with the Cys151 of Keap1 via Michael addition. The top-ranked ligand-protein complexes attained dynamic stability at 50-ns simulations with high free energy of binding. The top-ranked compounds also conferred favorable in silico pharmacokinetic properties.

Significance: The study highlights the role of $U$. alba secondary metabolites as potential inhibitors against the aforementioned target proteins in an effort to discover new drug leads for cancer and Alzheimer's.
\end{abstract}

Keywords Annonaceae; Uvaria alba; ADMET; anti-phosphodiesterase; anticholinesterase; anticancer; molecular docking; molecular dynamics; electrophilic compounds; HOMO-LUMO; reaction thermochemistry; grandifloracin. 


\section{Introduction}

The cell cycle is tightly regulated by cyclic nucleotide signaling ascribed as a composite component of tumor pathogenesis. Impairments in the synthesis of cyclic adenosine monophosphate (cAMP) or cyclic guanosine monophosphate (cGMP) by regulating phosphodiesterase enzymes (PDEs) have been linked to cancer pathologies $[1,2]$. Among the eleven PDE enzyme families, PDE4 specifically catalyzes the hydrolysis of cAMP [1-3]. Tumor cells originating from the central nervous system, lung and breast have an upregulated PDE4 level that primarily drives cAMP hydrolysis [4]. Thus, PDE4 is an attractive target for cancer chemotherapy. PDE4 inhibitors suppress tumor growth and induce apoptosis in cancer cells [4]. In addition, there have been studies indicating that selective inhibition of PDE4 may potentially treat neurodegenerative disorders, including Alzheimer 's disease (AD) [5]. Similarly, inhibition of acetylcholinesterase enzyme $(\mathrm{AChE})$ represents a therapeutic strategy for managing $\mathrm{AD}$. $\mathrm{AChE}$ catalyzes the hydrolysis of acetylcholine that is vital in memory formation [6]. Several preclinical studies indicate PDE4 and AChE inhibitors mitigate deficits in long-term memory caused by oxidative stress, aging and overexpression of amyloid-beta plaques and neurofibrillary tangles in brain tissues. Thus, PDE4 and AChE inhibitors hold promise in the treatment of neurodegenerative and inflammatory diseases [7].

Molecular docking and molecular dynamics simulations are popular computational methodologies adopted for drug discovery [8]. Among the recently discovered drug targets using computational techniques is the ubiquitin-proteasome pathway, which is involved in the synchronized proteolysis of cyclins and cyclin-dependent kinase inhibitors critical for cell cycle

progression $[9,10]$. Protein ubiquitination is primarily regulated by deubiquitinases (DUBs). Thus, inhibiting DUBs, such as ubiquitin specific peptidase 14 (USP14), may induce apoptosis in 
a variety of cancer cells while conferring low cytotoxicity to normal cells [10]. Another cytoprotective mechanism of the body against oxidative stress involves the KEAP1-Nrf2-ARE pathway [11]. Oxidative stress is the underlying contributor to virtually every chronic disease. Recent studies showed that disrupting the KEAP1-Nrf2-ARE pathway and consequently enhancing Nrf2 activity is a promising strategy for preventing chronic diseases involving oxidative stress and inflammation [12]. Natural products, particularly those with unsaturated electrophilic moieties, have been identified to target USP14 and KEAP1 [10,13].

The genus Uvaria (family Annonaceae) is a prolific source of pharmacologically active natural products. Chemical efforts on different species elaborated secondary metabolites with wide array of biological activities including anti-cancer, anti-inflammatory, antitubercular, antioxidant and antimicrobial activities [14-21]. Despite numerous studies on several species of the genus Uvaria, limited efforts describing the phytochemical constituents and biological activities are reported for the endemic Philippine medicinal plant, Uvaria alba. Thus, our present investigation is focused on the in vitro evaluation of the antiproliferative, anticholinesterase and antiphosphodiesterase activities of the DCM sub-extract of $U$. alba. We performed computationaldriven drug discovery efforts, specifically molecular docking and molecular dynamics simulations, to identify specific inhibitors from $U$. alba that could target USP14, KEAP1, PDE4 B2B and AChE enzymes. At the same time, a density functional theory calculation was also done to model a possible Michael addition reaction of the metabolites with KEAP1.

\section{Materials and methods}

\subsection{Collection and identification of plant material}

The leaves of Uvaria alba were collected in the lowlands of Palauig, Zambales, Luzon, Philippines $\left(15^{\circ} 43^{\prime} \mathrm{N}, 119^{\circ} 91^{\prime}\right.$ E) in October 2013. These were authenticated with voucher 
specimens (USTH 1631) deposited at the University of Santo Tomas Herbarium and at the Philippine National Herbarium, Manila, Philippines.

\subsection{Crude extraction and fractionation}

The ground air-dried leaves $(2.1 \mathrm{~kg})$ were extracted with technical-grade (1:1) DCM$\mathrm{MeOH}$ and concentrated in vacuo at $45{ }^{\circ} \mathrm{C}$. A $349.3 \mathrm{~g}$ of crude DCM-MeOH extract (Ua) was yielded. Ua crude extract was suspended in distilled water and partitioned according to increasing polarity yielding three sub-extracts namely, petroleum ether (UaP), DCM (UaD) and $n$-butanol (UaB) sub-extracts. The sub-extracts were concentrated in vacuo and tested for biological activities.

\subsection{Anti-proliferative and cytotoxicity assay}

The antiproliferative and cytotoxic properties of the plant samples were assessed using CellTiter-Blue assay as previously described [16, 20, 22]. The antiproliferation assay was carried out by testing the test substance dissolved in DMSO against chronic myelogenous leukemia (K562, DSM ACC 10) and human umbilical vein endothelial cells (HUVEC, CRL-1730). Meanwhile, cytotoxicity assessment was carried out on the subconfluent monolayers of human cervical cancer cells (HeLa, DSM ACC 57). Optical densities were measured at $660 \mathrm{~nm}$ in SUNRISE microplate reader (TECAN, Crailsheim, Germany). The GI 50 and $\mathrm{CC}_{50}$ values were defined as being where the dose response curve intersected the $50 \%$ line compared to untreated control. These values were determined using the software Magellan (TECAN). Doxorubicin (DOX) was used as the reference drug. Selectivity index was computed for those samples with antiproliferative property using the formula: GI ${ }_{50} \mathrm{HUVEC} / \mathrm{GI}_{50} \mathrm{~K}-562$ [16, 22].

\subsection{Acetylcholinesterase (AChE) inhibition assay}


Acetylcholinesterase inhibitory property was evaluated using slightly modified Ellman's assay [24]. Electric eel AChE (type-VI-S, EC 3.1.1.7, Sigma) was used as the enzyme source while acetylthiocholine iodide (ATCI, Sigma, St. Louis, MO, USA) was used as the substrate of the reaction. 5,5-dithiobis-(2-nitrobenzoic acid) (Sigma, St. Louis, MO, USA) was used for the measurement of the cholinesterase activity. Test samples were reconstituted with 50\% DMSO. About $140 \mu \mathrm{L}$ of $0.1 \mathrm{mM}$ sodium phosphate buffer (pH 8.0), $20 \mu \mathrm{L}$ of $3 \mathrm{mM}$ DTNB, and $20 \mu \mathrm{L}$ of $0.36 \mathrm{U} / \mathrm{mL}$ of $\mathrm{AChE}$ were added in the reaction, followed by incubation for $15 \mathrm{~min}$ at $37^{\circ} \mathrm{C}$ and addition of $10 \mu \mathrm{L}$ of $15 \mathrm{mM}$ ATCI. The microplates were then read at $412 \mathrm{~nm}$ using Glomax microplate reader (Promega, Madison, Wisconsin). Galanthamine was used as the reference drug. $\mathrm{IC}_{50}$ value is defined as the concentration of the plant material required to inhibit $\mathrm{AChE}$ activity by $50 \%$.

\subsection{Phosphodiesterase (PDE4 B2) inhibition assay}

The effect of $U$. alba DCM sub-extract on human recombinant cAMP-specific phosphodiesterase (PDE4 B2) was carried out with the diluted test sample in $20 \mu \mathrm{L}$ of $50 \mathrm{mM}$ Tris- $\mathrm{HCl}$ buffer ( $\mathrm{pH} 7.5$ ) containing $8.3 \mathrm{mM} \mathrm{MgCl}_{2}, 1.7 \mathrm{mM}$ EGTA and $5 \mathrm{U}$ recombinant human cAMP specific PDE 4B2 (Biocat 60042-BPS, Heidelberg, Germany). The reaction was started with $20 \mu \mathrm{L}$ of $24 \mu \mathrm{M}$ cAMP (Sigma A9501, Taufkirchen, Germany) dissolved in $50 \mathrm{mM}$ Tris-HCl buffer (pH 7.5) containing $8.3 \mathrm{mM} \mathrm{MgCl} 2$ and $1.7 \mathrm{mM}$ EGTA. After an incubation period of 30 min at $30^{\circ} \mathrm{C}$, the reaction was stopped and the AMP concentration was quantified with the PDELight HTS cAMP Phosphodiesterase Assay Kit (Lonza, LT07-600, Koeln, Germany) following the manufacturer's instructions. The luminescence was measured using the microtiter plate reader Infinite M200 (TECAN) with $0.1 \mathrm{~s}$ integration time. Rolipram was used as the 
reference PDE inhibitor drug. $\mathrm{IC}_{50}$ value is defined as the concentration of the plant material required to inhibit PDE4 B2 activity by 50\% [25].

\subsection{Liquid chromatography - high-resolution mass spectrometric (LC-MS) analysis}

The $U$. alba DCM sub-extract (UaD), being the most biologically active, was chemically profiled for the identification of its putative secondary metabolites using LC-HR-ESIMS-QToF performed on a Shimadzu LC-20 AD apparatus equipped with an autosampler (SIL-20A, Shimadzu), diode array detector (SPD-M20AV, Shimadzu) and coupled with a micrOTOFII (Bruker Daltonics) ESI-qTOF mass spectrometer. HPLC column Chromolith Performance RP-18e ( $2.0 \times 100 \mathrm{~mm}$ i.d.) was used for the analysis. The eluents were acetonitrile and water with $0.1 \%$ acetic acid. After injecting $5 \mu \mathrm{L}$ of the UaD sub-extract, flow elution was set at $2 \mathrm{~mL} / \mathrm{min}$. The effluents were monitored at $350 \mathrm{~nm}$. The mass spectra were recorded in the mass range $\mathrm{m} / \mathrm{z} 50$ to 2000. The Xcalibur 2.2 software (Thermo Fisher Scientific, USA) was used for data acquisition and analysis.

\subsection{Molecular docking}

The binding affinities of the ligands from $\mathrm{UaD}$ to the docking sites of PDE4 B2B (PDB ID: 1RO6), AChE (PDB ID:4EY6), USP14 (PDB ID:6IIM), KEAP1-Kelch domain (PDB ID: 4L7B), and KEAP1-BTB domain (PDB ID:5DAD) were calculated (Figure 1). Molecular docking experiments were performed on the UCSF Chimera platform [26]. The three-dimensional structures of the protein were added to the docking platform as PDB formats. Each protein crystal structure was processed by removing existing co-crystallized ligands and water molecules. Meanwhile, the ligands were added to the docking platform, rendered from SMILES notation or added as SYBYL mol2 file. Minimization and dock-prepping of ligand and protein structures 
were done by adding the missing hydrogen atoms and appropriate charges to the structures employing the Gasteiger charge method computed using Amber's Antechamber module [27]. The docking procedure was done using flexible ligand into flexible active site protocol, where the ligand was allowed to be flexible and torsion within a grid box encompassing the ligand-binding cavity of each enzyme, predicted using $\mathrm{COACH}$ algorithms [28]. With all docking parameters maintained at default values, molecular docking simulation was performed following the BroydenFletcher-Goldfarb-Shanoo (BFGS) algorithm of AutoDock Vina (version 1.1.2) [29]. After each run, Autodock Vina provides a set of docking poses for each ligand with calculated binding affinities in which the docking pose with best affinity was chosen to represent the set. This was then subjected to post-dock analysis. Visualization and analysis of the enzyme-ligand complex conformation were carried out using UCSF Chimera and Biovia Discovery Studios (version 4.1).

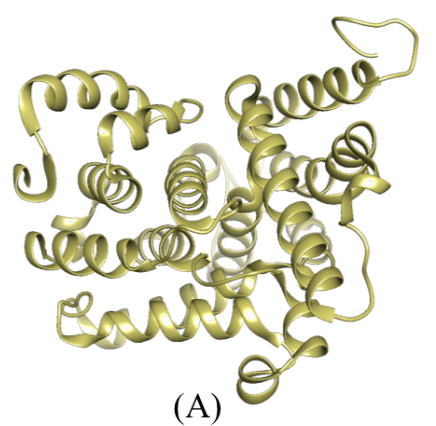

(A)

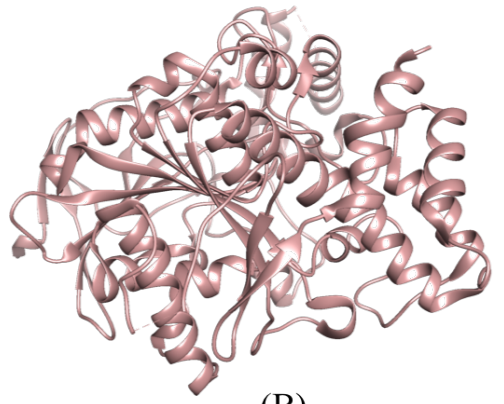

(B)

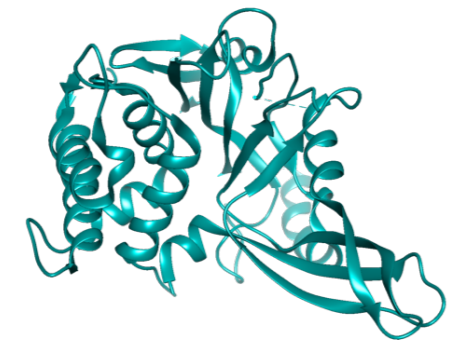

(C)

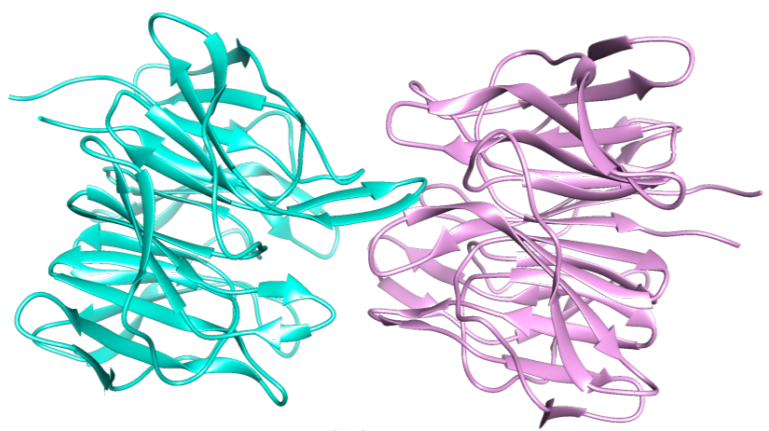

(D)

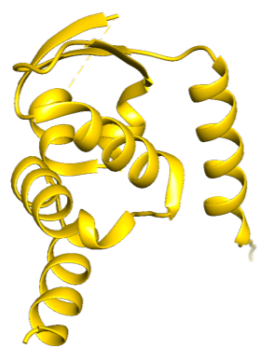

(E) 
Figure 1. Structures of target enzymes/proteins: (A) phosphodiesterase 4 B2B, PDE4 B2B, (B) acetylcholinesterase, AChE, (C) ubiquitin specific peptidase 14, USP14, (D) KEAP1-Kelch domain, and (E) KEAP1-BTB domain.

\subsection{Molecular dynamics simulation}

The molecular dynamics behavior of the top scoring complexes was simulated using Amber 18 [30]. Drug topologies were generated using antechamber [31]. With TIP3P water box and $\mathrm{Na}^{+}$ions, the systems were solvated and neutralized. Gentle energy minimization in two steps was performed to relax all the systems followed by heating. PME (Particle Mesh Ewald) algorithm for short and long range interactions was also used. Finally, a total of $50 \mathrm{~ns}$ simulation for each system was performed [32]. CPPTRAJ and PTRAJ were used to evaluate the trajectories for stability (RMSD) and residual flexibility (RMSF) [33].

\subsection{Binding free energy calculation}

Trajectories from molecular dynamics simulations were subjected to binding free energy calculations using the MMPBSA.py script [34]. This method is widely implemented by different studies to calculate the binding energy of a ligand-protein, protein-protein and protein-nucleic acid complexes [35-37]. The total binding energy $(\Delta \mathbf{G})$ was then calculated using the equation:

$$
\Delta \mathbf{G}_{\text {bind }}=\Delta \mathbf{G}_{\text {complex }}-\left[\Delta \mathbf{G}_{\text {receptor }}+\Delta \mathbf{G}_{\text {ligand }}\right]
$$

To further understand each energy term such as electrostatic energy, Van der Waals forces, polar and nonpolar interactions which may contribute to the total energy $(\mathbf{G})$, the equation below was used:

$$
\mathbf{G}=\mathbf{G}_{\text {bond }}+\mathbf{G}_{\text {ele }}+\mathbf{G}_{\mathrm{vdW}}+\mathbf{G}_{\mathrm{pol}}+\mathbf{G}_{\mathrm{npol}}-\mathbf{T S}
$$




\subsection{Reaction thermochemistry and frontier molecular orbital energy calculation}

All calculations were performed within the Gaussian16W suite of programs [38]. Initial conformational searches of all species were performed by scanning all freely rotating dihedral angles at the Hartree-Fock level of theory and $6-31 \mathrm{G}^{* *}$ basis set to locate their approximate global energy minimum structures prior to full geometry optimization. Frontier molecular orbital energies [highest occupied molecular orbital (HOMO, Еномо) and lowest unoccupied molecular orbital (LUMO, ELUMO)] of the electrophilic $U$. alba metabolites, the Michael acceptors, were calculated for their empirical global electrophilicity index $(\boldsymbol{\omega})[39,40]$ :

$$
\omega=\mu^{2} / 2 \eta
$$

where $\boldsymbol{\mu}$ is the chemical potential or the first derivative of total energy, $\boldsymbol{E}$, with respect to the electron number, $\boldsymbol{N}$, (eqn 4 ) and $\boldsymbol{\eta}$ is the hardness or the second derivative of total energy with respect to the electron number (eqn 5).

$$
\begin{gathered}
\mu=\left(\frac{\partial E}{\partial N}\right)_{v(r)} \approx \frac{E_{\text {HOMO }}+E_{L U M O}}{2} \\
\eta=\left(\frac{\partial^{2} E}{\partial N^{2}}\right)_{v(r)} \approx E_{L U M O}-E_{\text {HOMO }}
\end{gathered}
$$

Geometry optimization and energy calculation of the stable species of the proposed Michael addition mechanism was performed via density functional theory (DFT) B3LYP/6$31 \mathrm{G}^{* *}(\mathrm{~d}, \mathrm{p})[41]$. Approximate locations of transition states (TS) were determined by performing relaxed potential energy surface scans as well as refinement of the transition state structure using TS Berney and QST3 optimization at the same level of theory. The TS was confirmed by intrinsic reaction coordinate (IRC) calculations and were distinguished as having a single imaginary vibrational frequency. All potential energy surface scans, geometry optimizations, and single-point calculations were performed at $298.15 \mathrm{~K}, 1.0 \mathrm{~atm}$ pressure, and in a polarized continuum model (PCM) solvent for water. 


\subsection{ADMET profiling}

Computational prediction of the absorption, distribution, metabolism, and excretion (ADME) properties of secondary metabolites from UaD was carried out using SwissADME software (Molecular Modeling Group, Swiss Institute of Bioinformatics, 2019). Pharmacokinetic profiles were evaluated according to Lipinski's 'rule-of-five' which analyzes the biochemical features of a drug that may influence its absorption and permeation across cell membranes. For a compound to exhibit drug likeness, at least three of the following Lipinski's criteria must be fulfilled: molecular weight $<500$ Daltons $(\mathrm{Da})$, calculated lipophilicity $(\log \mathrm{P})<5$, number of hydrogen-bond acceptors $<10$, and number of hydrogen-bond donors $<5$ [18]. Furthermore, OSIRIS property explorer program (Thomas Sander, Idorsia Pharmaceuticals Ltd., 2017) was employed for in silico toxicity prediction which takes into account the potential mutagenicity, tumorigenicity, irritant effects, and reproductive toxicity of the UaD secondary compounds [42].

\section{Results}

\subsection{Antiproliferative, anticholinesterase and phosphodiesterase inhibitory properties in vitro}

Anti-proliferative and cytotoxic activities of $U$. alba were assessed using CellTiter-Blue assay (Table 1, Figure 2). The dichloromethane (UaD) and petroleum ether (UaP) sub-extracts were antiproliferative against chronic human myelogous leukemia cells (K-562) with GI 50 values of 12.3 and $16.7 \mu \mathrm{g} / \mathrm{mL}$, respectively. Interestingly, $\mathrm{UaD}$ was selective against HUVEC with $\mathrm{GI}_{50}$ of $24.1 \mu \mathrm{g} / \mathrm{mL}$. Interestingly, the crude extract Ua was cytostatic to HeLa. Likewise, the subextracts $\mathrm{UaD}$ and $\mathrm{UaP}$ elicited cytostatic effects. An extract or plant component is deemed cytostatic if it inhibits cell proliferation over a large range of concentration compared to the 
reference drug. Doxorubicin, on the other hand, was cytotoxic to $\mathrm{HeLa}$ with $\mathrm{CC}_{50}$ value of 2.0 $\mu \mathrm{g} / \mathrm{mL}$.

Table 1. Antiproliferative, anti-phosphodiesterase (PDE4 B2) and anticholinesterase (AChE) activities of Uvaria alba.

\begin{tabular}{|c|c|c|c|c|c|c|}
\hline \multirow[t]{2}{*}{ Sample } & \multicolumn{2}{|c|}{$\begin{array}{c}\text { Antiproliferative } \\
\text { activity } \\
\mathrm{GI}_{50}(\mu \mathrm{g} / \mathrm{mL})\end{array}$} & \multirow{2}{*}{$\begin{array}{c}\begin{array}{c}\text { Selectivity } \\
\text { index }\end{array} \\
\left(\mathrm{GI}_{50} \mathrm{HUVEC} /\right. \\
\left.\mathrm{GI}_{50} \mathrm{~K}-562\right)\end{array}$} & \multirow{2}{*}{$\begin{array}{c}\text { Cytotoxicity } \\
\mathrm{CC}_{50}(\mu \mathrm{g} / \mathrm{mL}) \\
\text { HeLa }\end{array}$} & \multirow[t]{2}{*}{$\begin{array}{c}\text { Anti-PDE 4B2 } \\
\mathrm{IC}_{50}(\mu \mathrm{g} / \mathrm{mL})\end{array}$} & \multirow[t]{2}{*}{$\begin{array}{l}\text { Anti-AChE } \\
\text { IC }_{50}(\mu \mathrm{g} / \mathrm{mL})\end{array}$} \\
\hline & HUVEC & K-562 & & & & \\
\hline Ua crude & $>50$ & $>50$ & - & cytostatic & $>20$ & $0.25 \pm 0.03$ \\
\hline UaB & $>50$ & $>50$ & - & $>50$ & $>20$ & $0.24 \pm 0.01$ \\
\hline UaP & $21.3 \pm 0.7$ & $16.7 \pm 1.6$ & 1.28 & cytostatic & $>20$ & $0.25 \pm 0.02$ \\
\hline $\mathrm{UaD}$ & $24.1 \pm 1.6$ & $12.3 \pm 1.8$ & 1.96 & cytostatic & $16.8 \pm 3.89$ & $0.22 \pm 0.01$ \\
\hline Doxorubicin & $0.1 \pm 0.5$ & $1.0 \pm 0.6$ & 0.10 & $2.0 \pm 0.8$ & - & - \\
\hline Rolipram & - & - & - & - & $0.22 \pm 0.10$ & - \\
\hline Galantamine & - & - & - & - & - & $0.14 \pm 0.01$ \\
\hline
\end{tabular}

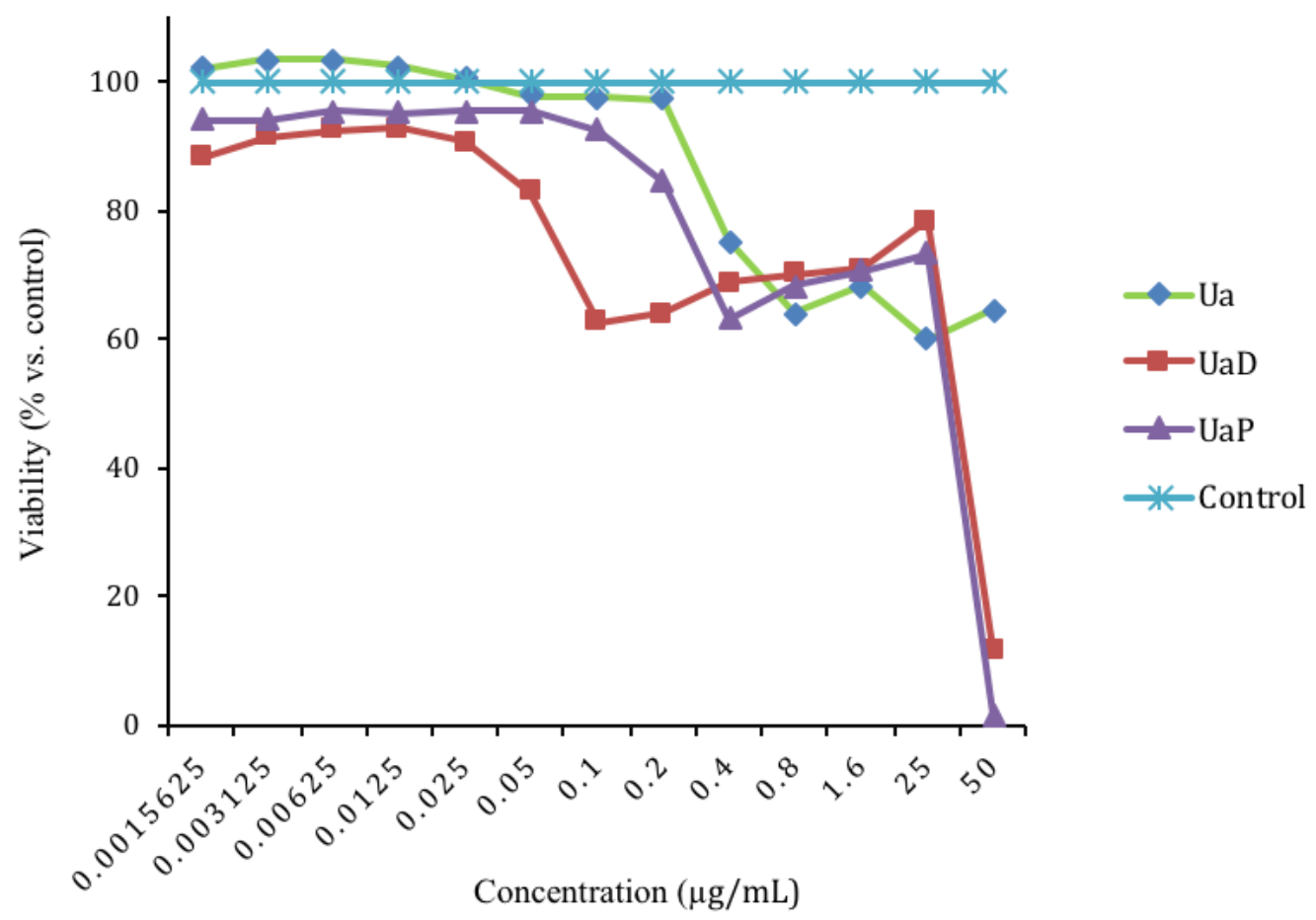

Figure 2. Cytostatic curve of the dichloromethane $(\mathrm{UaD})$ and petroleum ether $(\mathrm{UaP})$ sub-extracts from Uvaria alba. 
Apart from its potential anticancer properties, U. alba inhibited acetylcholinesterase (AChE) and phosphodiesterase (PDE 4B2) in comparison to the standard drugs galantamine ( $\mathrm{IC}_{50}$ $=0.14 \mu \mathrm{g} / \mathrm{mL})$ and rolipram $\left(\mathrm{IC}_{50}=0.22 \mu \mathrm{g} / \mathrm{mL}\right)$. Among the sub-extracts, $\mathrm{UaD}$ consistently showed potent inhibitory properties against $\mathrm{AChE}$ and PDE4 B2 with $\mathrm{IC}_{50}$ values of 0.22 and 16.8 $\mu \mathrm{g} / \mathrm{mL}$, respectively (Table 1 ).

\subsection{LC-MS analysis of DCM sub-extract UaD}

The chemical constituents previously reported from genera of the family Annonaceae, especially Uvaria, were matched with the pseudomolecular ion peaks (under both positive and negative modes) generated during the LC-HR-ESIMS-QToF experiments (Fig. S1-S18). According to high-resolution molecular ion masses and retention time informations, eighteen compounds; 7-benzoyloxy-2H-1-benzopyran-2-one (1), uvaridapoxide A (2), microcarpin A (3), microcarpin B (4), grandiuvarone (5), uvaridacane A (6), valderramenol A (7), 3-(3,4dihydroxybenzyl)-3',4',6-trihydroxy-2,4-dimethoxychalcone (8), albanol A (9), tepanone (10), valderramenol B (11), 5-O-methylchamanetin (12), cyathosthemine (13), bractelactone (14), grandifloracin (15), dichamanetin (16), albanol B (17) and cyathoviridine (18) (Figure 3) were identified (Table 2). These compounds were generally reported to confer cytotoxic and antiinflammatory properties. 
Table 2. Putative compounds 1-18 identified from the DCM sub-extract and their associated

biological activities.

\begin{tabular}{|c|c|c|c|c|c|c|}
\hline Compound & $\begin{array}{c}\text { Retention } \\
\text { Time } \\
\left(t_{R}, \mathrm{~min}\right) \\
\end{array}$ & $\begin{array}{c}\text { Molecular ion peak } \\
(\mathrm{m} / \mathrm{z})\end{array}$ & $\begin{array}{l}\text { Calculated } \\
\text { Mass }\end{array}$ & $\begin{array}{l}\text { Molecular } \\
\text { Formula }\end{array}$ & Compound Identity & $\begin{array}{c}\text { Reported Biological } \\
\text { Activity }\end{array}$ \\
\hline 1 & 13.0 & $265.0483[\mathrm{M}-\mathrm{H}]^{-}$ & 265.2482 & $\mathrm{C}_{16} \mathrm{H}_{10} \mathrm{O}_{4}$ & $\begin{array}{l}\text { 7-Benzoyloxy-2H-1- } \\
\text { benzopyran-2-one }\end{array}$ & No reported activity \\
\hline 2 & 16.2 & $409.1246[\mathrm{M}+\mathrm{H}]^{+}$ & 408.4007 & $\mathrm{C}_{23} \mathrm{H}_{20} \mathrm{O}_{7}$ & Uvaridapoxide A & $\begin{array}{c}\text { Antiausterity and } \\
\text { cytotoxic activities in } \\
\text { human pancreatic cancer } \\
\text { PANC-1 } \\
{[43]}\end{array}$ \\
\hline 3 & 16.4 & $385.1295[\mathrm{M}-\mathrm{H}]^{-}$ & 386.3952 & $\mathrm{C}_{21} \mathrm{H}_{22} \mathrm{O}_{7}$ & Microcarpin A & No reported activity \\
\hline 4 & 16.5 & $385.1294\left[^{\mathrm{M}-\mathrm{H}}\right]^{-}$ & 386.3952 & $\mathrm{C}_{21} \mathrm{H}_{22} \mathrm{O}_{7}$ & Microcarpin B & $\begin{array}{c}\text { No reported activity } \\
\text { Antitubercular activity; } \\
\text { antiproliferative }\end{array}$ \\
\hline 5 & 16.7 & $325.0679[\mathrm{M}+\mathrm{Na}]^{+}$ & 325.0691 & $\mathrm{C}_{16} \mathrm{H}_{14} \mathrm{O}_{6} \mathrm{Na}$ & Grandiuvarone & $\begin{array}{c}\text { and cytotoxic activities in } \\
\text { HeLa and KB-562 } \\
{[16,17]}\end{array}$ \\
\hline 6 & 17.5 & $311.1852[\mathrm{M}+\mathrm{H}]^{+}$ & 311.1283 & $\mathrm{C}_{19} \mathrm{H}_{19} \mathrm{O}_{4}$ & Uvaridacane A & $\begin{array}{c}\text { Antiausterity and } \\
\text { cytotoxic activities in } \\
\text { human pancreatic cancer } \\
\text { PANC-1 } \\
\text { [43] }\end{array}$ \\
\hline 7 & 18.6 & $435.1462[\mathrm{M}-\mathrm{H}]^{-}$ & 435.4539 & $\mathrm{C}_{25} \mathrm{H}_{24} \mathrm{O}_{7}$ & Valderramenol A & Anti-tubercular activity \\
\hline 8 & 18.7 & $437.1243\left[^{[\mathrm{M}-\mathrm{H}}\right]^{-}$ & 437.4267 & $\mathrm{C}_{24} \mathrm{H}_{22} \mathrm{O}_{8}$ & $\begin{array}{l}\text { 3-(3,4-Dihydroxy } \\
\text { benzyl)-3',4',6- } \\
\text { trihydroxy-2,4- } \\
\text { dimethoxychalcone }\end{array}$ & No reported activity \\
\hline
\end{tabular}




\begin{tabular}{|c|c|c|c|c|c|c|}
\hline 9 & 19.0 & $469.1025[\mathrm{M}+\mathrm{Na}]^{+}$ & 469.8673 & $\mathrm{C}_{23} \mathrm{H}_{23} \mathrm{ClO}_{7} \mathrm{Na}$ & Albanol A & $\begin{array}{l}\text { Cytotoxic and apoptosis- } \\
\text { inducing activities in } \\
\text { HL60 cells; inhibitory } \\
\text { activity in human DNA } \\
\text { topoisomerases I and II } \\
\text { [44] }\end{array}$ \\
\hline 10 & 19.2 & $315.1225[\mathrm{M}+\mathrm{H}]^{+}$ & 315.3325 & $\mathrm{C}_{18} \mathrm{H}_{18} \mathrm{O}_{5}$ & Tepanone & $\begin{array}{c}\text { Cytotoxic activity in } \\
\text { triple-negative breast } \\
\text { cancer cells and human } \\
\text { promyelocytic leukemia } \\
\text { HL-60 }[45,46]\end{array}$ \\
\hline 11 & 19.4 & $421.1301\left[^{[M-H}\right]^{-}$ & 421.4273 & $\mathrm{C}_{24} \mathrm{H}_{22} \mathrm{O}_{7}$ & Valderramenol B & No reported activity \\
\hline 12 & 19.8 & $377.1378[\mathrm{M}+\mathrm{H}]^{+}$ & 377.4019 & $\mathrm{C}_{23} \mathrm{H}_{21} \mathrm{O}_{5}$ & $\begin{array}{c}5-O- \\
\text { Methylchamanetin }\end{array}$ & No reported activity \\
\hline 13 & 19.8 & $527.1720[\mathrm{M}-\mathrm{H}]^{-}$ & 527.5492 & $\mathrm{C}_{31} \mathrm{H}_{28} \mathrm{O}_{8}$ & Cyathosthemine & No reported activity \\
\hline 14 & 20.2 & $417.1309[\mathrm{M}+\mathrm{H}]^{+}$ & 417.4227 & $\mathrm{C}_{25} \mathrm{H}_{20} \mathrm{O}_{6}$ & Bractelactone & $\begin{array}{c}\text { Anti-inflammatory } \\
{[47]}\end{array}$ \\
\hline 15 & 20.4 & $511.1725[\mathrm{M}+\mathrm{Na}]^{+}$ & 511.13687 & $\mathrm{C}_{28} \mathrm{H}_{24} \mathrm{O}_{8} \mathrm{Na}$ & Grandifloracin & $\begin{array}{c}\text { Antiausterity } \\
\text { activity against human } \\
\text { pancreatic cancer PANC- } \\
1[48]\end{array}$ \\
\hline 16 & 20.8 & $469.1642[\mathrm{M}+\mathrm{H}]^{+}$ & 469.4973 & $\mathrm{C}_{29} \mathrm{H}_{24} \mathrm{O}_{6}$ & Dichamanetin & $\begin{array}{c}\text { Cytotoxic against the } \\
\text { cancer cells HT-29 } \\
\text { (colon), DU145 } \\
\text { (prostate), and MDA- } \\
\text { MB-231 (breast cancer) } \\
{[49,50]}\end{array}$ \\
\hline 17 & 21.1 & $405.1327[\mathrm{M}+\mathrm{H}]^{+}$ & 405.8488 & $\mathrm{C}_{21} \mathrm{H}_{22} \mathrm{ClO}_{6}$ & Albanol B & $\begin{array}{l}\text { Antitubercular activity; } \\
\text { antiproliferative }\end{array}$ \\
\hline
\end{tabular}


and cytotoxic activities in HeLa and KB-562

[16]

$\mathrm{C}_{25} \mathrm{H}_{24} \mathrm{O}_{7}$

Cyathoviridine

Cytotoxic in KB cells [51] 


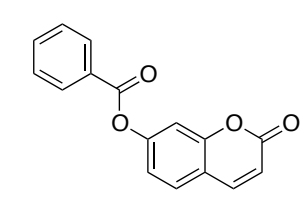

1

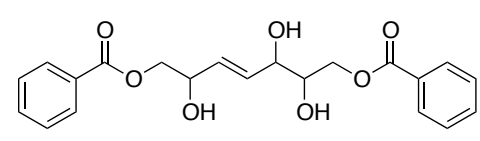

4

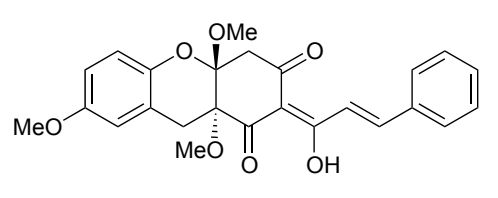

7

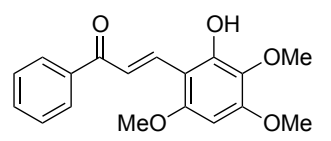

10
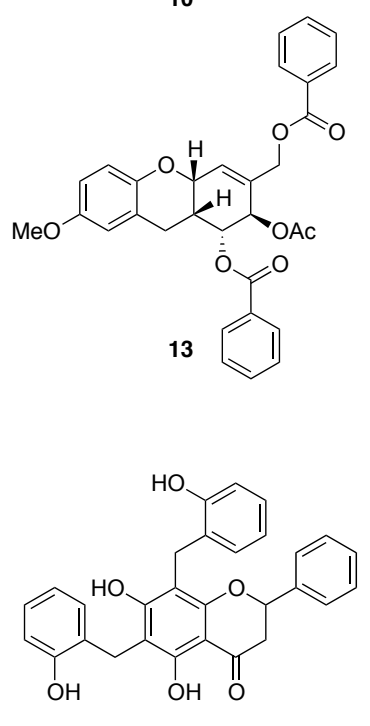

16
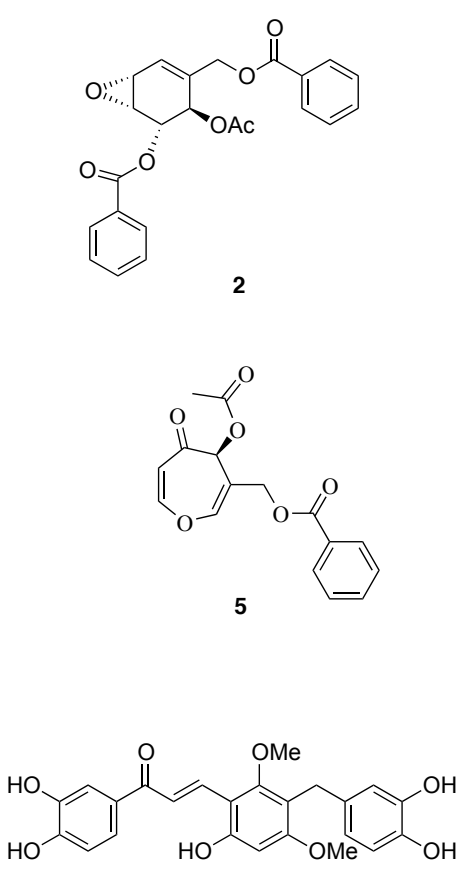

8

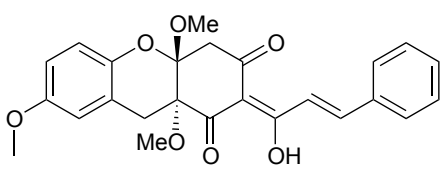

11

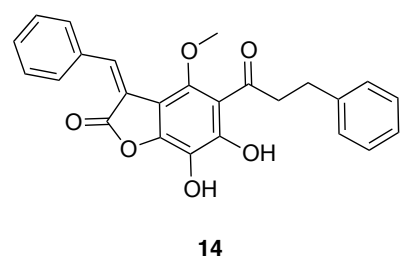

14

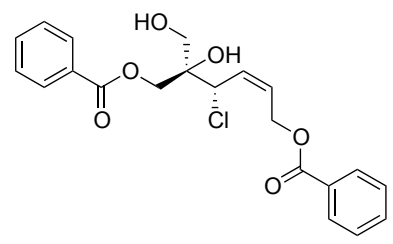

17
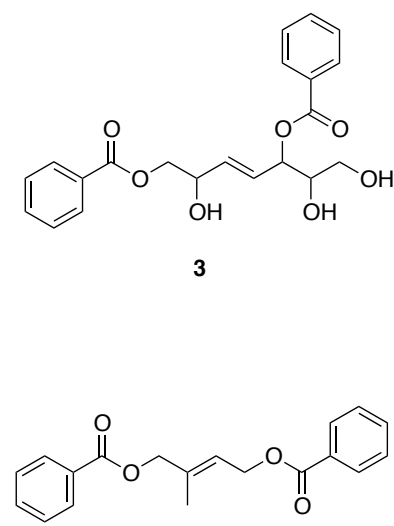

6

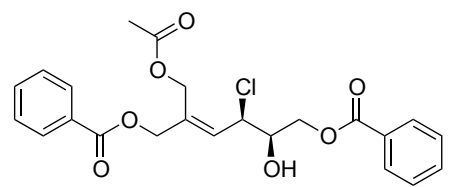

9

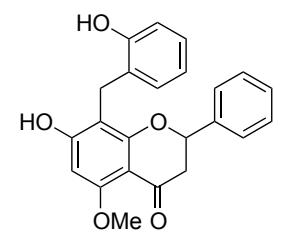

12
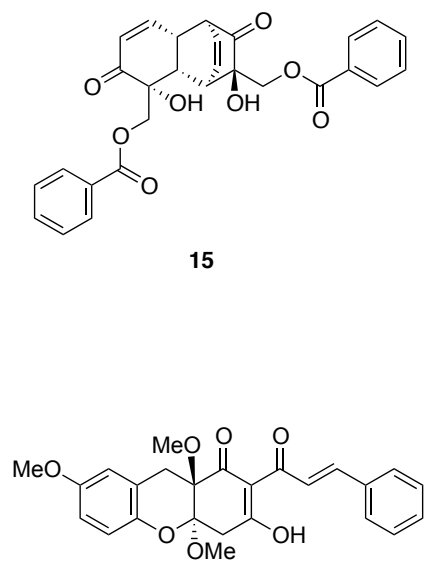

18

Figure 3. Structures of secondary metabolites 1-18 identified in DCM sub-extract of $U$. alba by LC-HR-ESIMS-QTof. 
Table 3. Binding energy values of $U$. alba DCM sub-extract secondary metabolites 1-18 against PDE4 B2B, AChE and KEAP1.

\section{Binding Energy (kcal/mol)}

\begin{tabular}{|c|c|c|c|c|c|}
\hline Compound & $\begin{array}{l}\text { PDE4 B2B } \\
\text { (PDB:1RO6) }\end{array}$ & $\begin{array}{c}\mathrm{AChE} \\
\text { (PDB:4EY6) }\end{array}$ & $\begin{array}{c}\text { USP14 } \\
\text { (PDB:6IIM) }\end{array}$ & $\begin{array}{c}\text { Keap-1 } \\
\text { (BTB) } \\
\text { (PDB:5DAD) }\end{array}$ & $\begin{array}{c}\text { Keap-1 } \\
\text { (Kelch) } \\
\text { (PDB:4L7B) }\end{array}$ \\
\hline 1 & -8.7 & -9.5 & -8.3 & -6.8 & -8.7 \\
\hline 2 & -7.9 & -9.4 & -8.4 & -6.4 & -8.9 \\
\hline 3 & -8.5 & -9.5 & -8.0 & -5.8 & -8.7 \\
\hline 4 & -8.7 & -9.6 & -7.7 & -5.8 & -7.9 \\
\hline 5 & -7.8 & -9.0 & -7.7 & -6.0 & -8.1 \\
\hline 6 & -8.7 & -9.4 & -7.5 & -5.9 & -8.3 \\
\hline 7 & -9.7 & -5.9 & -7.8 & -7.1 & -8.6 \\
\hline 8 & -9.5 & -9.8 & -8.4 & -7.1 & -10.1 \\
\hline 9 & -8.4 & -9.6 & -8.0 & -6.4 & -9.3 \\
\hline 10 & -8.1 & -8.9 & -7.0 & -5.9 & -8.0 \\
\hline 11 & -9.3 & -6.0 & -7.9 & -6.9 & -8.8 \\
\hline 12 & -9.7 & -9.2 & -9.4 & -6.8 & -9.7 \\
\hline 13 & -9.9 & -7.2 & -8.8 & -6.6 & -10.6 \\
\hline 14 & -10.1 & -9.7 & -8.0 & -6.8 & -8.6 \\
\hline 15 & -10.2 & -7.8 & -9.0 & -7.3 & -10.2 \\
\hline 16 & -10.2 & -9.5 & -9.8 & -6.7 & -11.1 \\
\hline 17 & -8.1 & -9.4 & -7.9 & -5.9 & -8.6 \\
\hline 18 & -8.3 & -7.0 & -7.4 & -6.6 & -8.9 \\
\hline rolipram & -8.1 & - & - & 一 & - \\
\hline galantamine & - & -9.5 & - & 一 & - \\
\hline B-AP15 & - & - & -7.7 & - & - \\
\hline $\begin{array}{c}\text { clobetasol } \\
\text { propionate }\end{array}$ & - & - & - & -5.1 & -8.5 \\
\hline
\end{tabular}




\subsection{Molecular docking to PDE4B2 and AChE}

The structure of phosphodiesterases (PDE's) are comprised of three domains with the catalytic domain being the most conserved among the PDE isoenzymes. PDE4 B2B, in particular, is comprised of $N$-terminal regulatory domain (residues 1-151), a catalytic domain (residues 152489) and a C-terminal domain (residues 490-568). To assess the binding characteristics of the identified compounds from the UaD sub-extract of $U$. alba, a molecular docking approach was performed against PDE4 B2B, directed to the binding domain of the enzyme. Of the eighteen secondary metabolites, the polyphenols showed remarkable binding characteristics with PDE4 B2B. Dichamanetin (16) and grandifloracin (15) displayed the highest binding affinity for the said enzyme with a binding energy (BE) of $-10.2 \mathrm{kcal} / \mathrm{mol}$ each (Table 3, Figure 4). Compound 16's attachment to the binding domain of the enzyme is mostly due to $p i-p i$ interplay occurring in four regions of the molecule: the chromanone core against Met347; a phenyl substituent against Phe414 and Phe446; 8-hydroxybenzyl against Tyr233 and Tyr410; and 6-hydroxyphenyl with Leu303. A hydrogen bonding was also observed between Asp392 and a hydroxyl substituent of the chromanone core. Grandifloracin (15), on the other hand, is strongly bound to the active site of the enzyme through intramolecular conventional hydrogen bonds with (a) a hydroxyl substituent against His234 and (b) the electronegative oxygens of two ester groups against Tyr233, His278, and Asn283. Additionally, a $p i$-anion, a $p i$-sigma, and a stacked $p i-p i$ interactions were observed between the aromatic benzoyl groups against Glu304, Ile410, and Phe446, respectively. Another notable compound that conferred strong binding affinity against PDE 4B2B is bractelactone (14) with $\mathrm{BE}$ of $-10.1 \mathrm{kcal} / \mathrm{mol}$. Bractelactone's (14) attachment to the putative binding was markedly strengthened by hydrogen bonding between two hydroxyl substituents of the benzofuranone core against His238, His274, Tyr233, and Asp392. The benzofuranone core is also stabilized by pi-pi 
interaction with His234 as well as a phenyl substituent with Ile410, Phe414, and Phe446. For compound 14, a pi-anion and a pi-sulfur intermolecular attraction was observed between Glu304 against the compound's xanthone core and Cys432 against a benzoyl substituent. The rest of the structure is stabilized by $p i-p i / p i$-alkyl interactions and a hydrogen bonding.
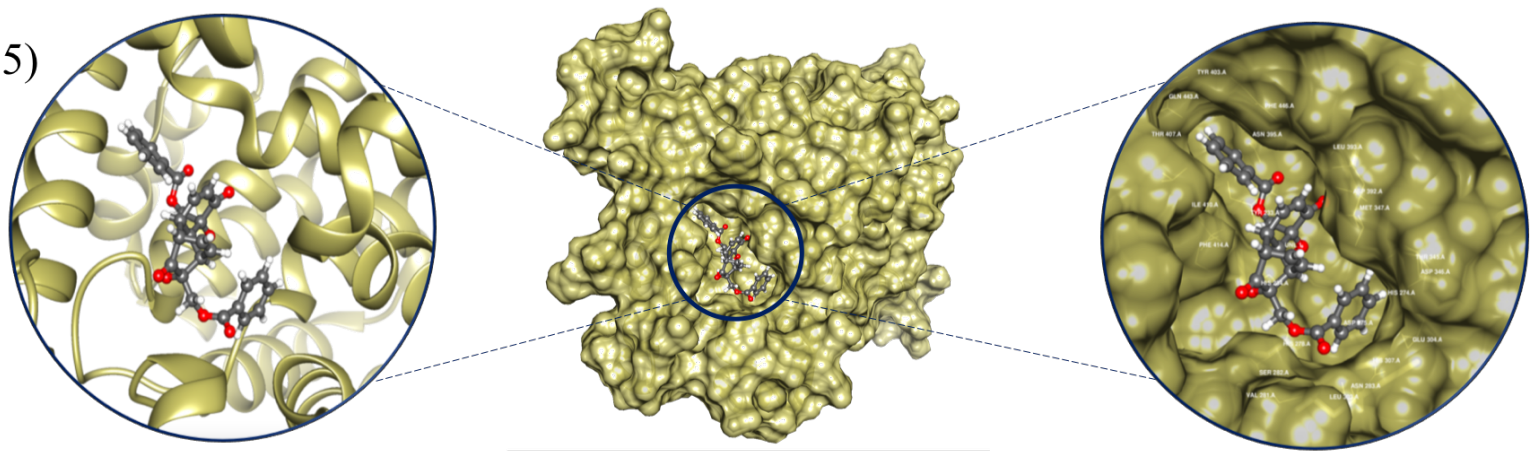

(16)
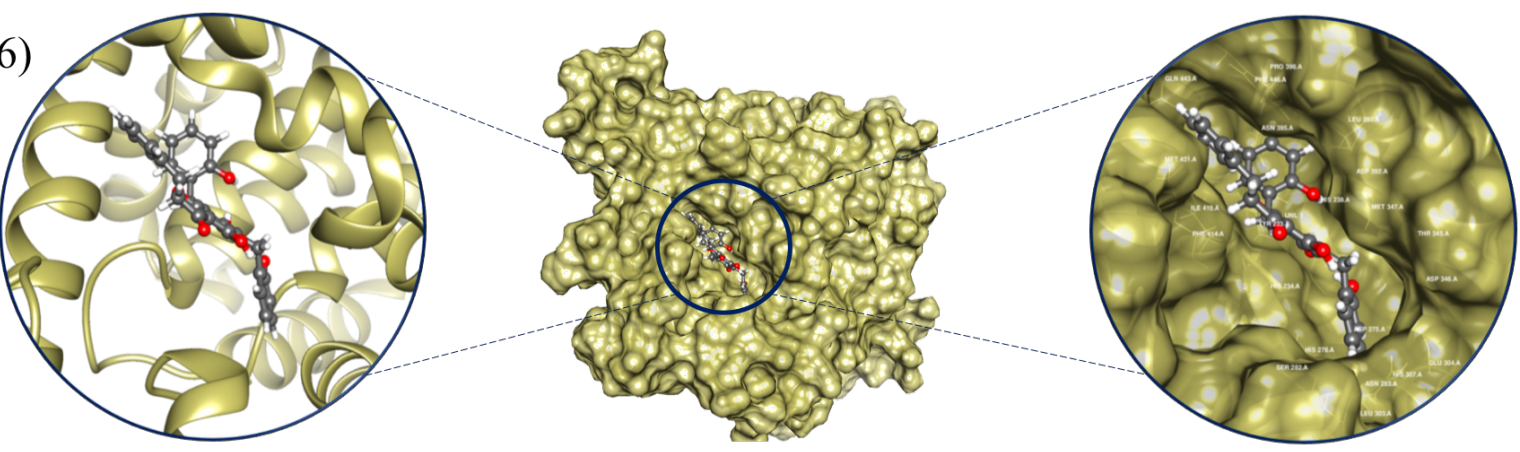

(14)
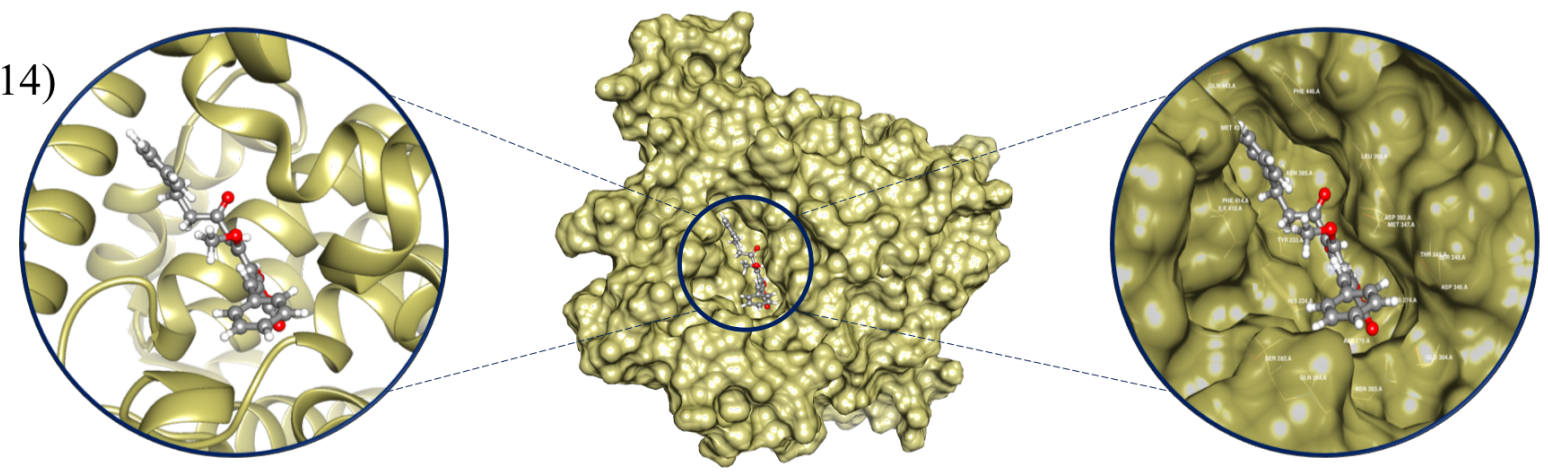

Figure 4. Docked poses of grandifloracin (15), dichamanetin (16), and bractelactone (14) against PDE4 B2B (PDB ID: 1RO6).

The secondary metabolites from the UaD sub-extract of $U$. alba were also tested for in silico binding towards acetylcholinesterase (AChE). Of which, the most notable compound is the 
polyphenol 3-(3,4-dihydroxybenzyl)-3',4',6-trihydroxy-2,4-dimethoxychalcone (8) with a BE of $9.8 \mathrm{kcal} / \mathrm{mol}$ (Table 3, Figure 5). The chalcone core of $\mathbf{8}$ is bound to the binding site via hydrogen bonding formed between Ser293 and Arg296 and the two hydroxyl substituents, $p i$ interactions with Tyr124 and Trp286, and a pi-lone pair attraction with Tyr337. The rest of the structure is likewise stabilized by vdW forces. Another chalcone hybrid, bractelactone (14), also exhibited a significant binding affinity with $\mathrm{AChE}(\mathrm{BE}=-9.8 \mathrm{kcal} / \mathrm{mol})$. Post-docking analysis revealed that compound $\mathbf{1 4}$ is completely nestled onto the AChE's active site gorge with which the enzymeligand complex is stabilized mostly by $p i-p i$ stacking interplay with aromatic components of the structure against Trp86, Tyr124, Trp286, and His447. Another distinct interaction for this complex involves a H-bonding between a hydroxyl substituent and Gln71.

(8)
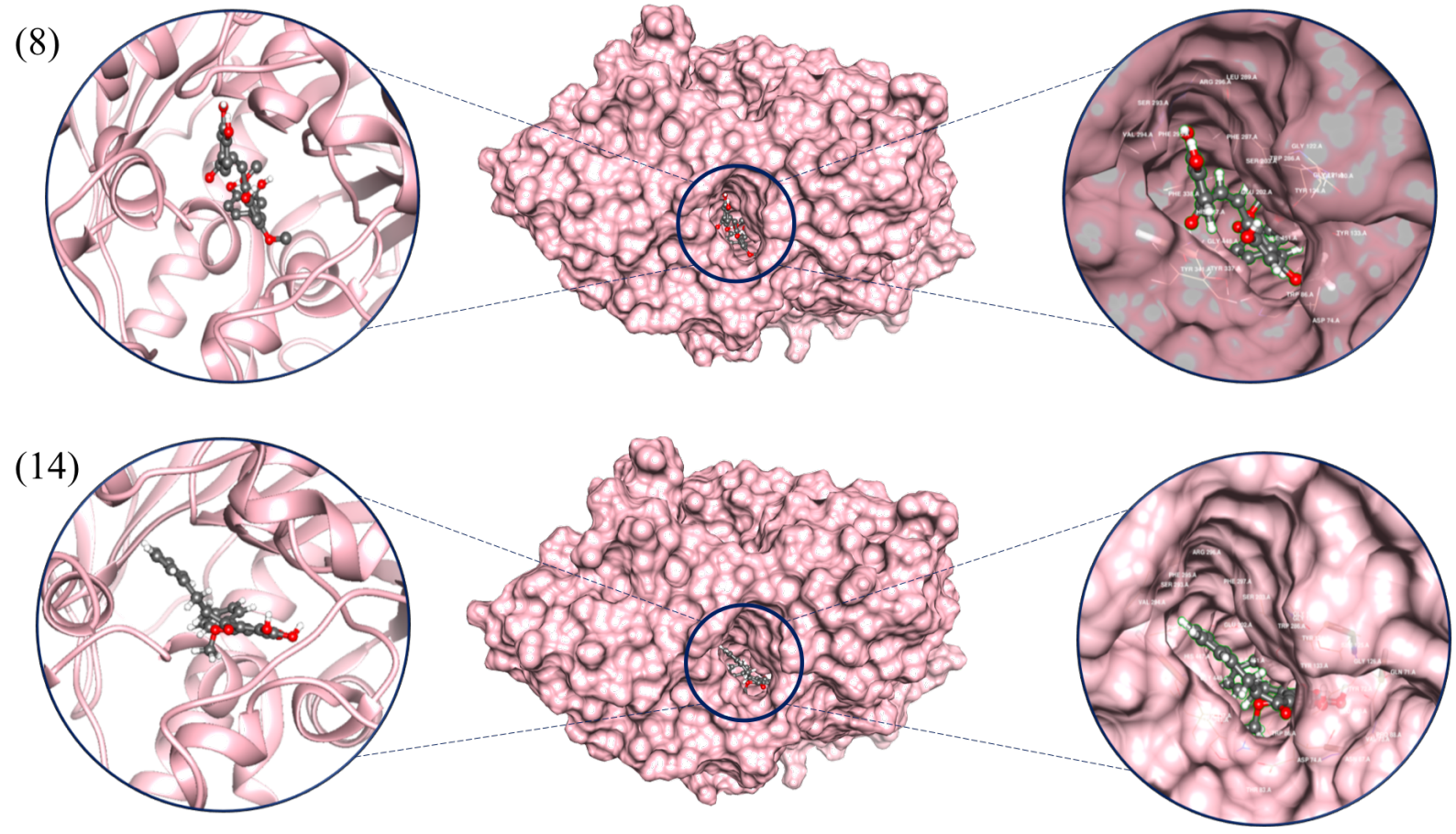

Figure 5. Docked poses of 3-(3,4-dihydroxybenzyl)-3',4',6-trihydroxy-2,4-dimethoxychalcone (8) and bractelactone (14) against AChE (PDB ID: 4EY6). 


\subsection{Molecular docking to USP14 and KEAP1 (Kelch and BTB domains)}

Via molecular binding-based screening, two benzylated hydroxyflavones, dichamanetin (16) and 5-O-methylchamanetin (12), were identified to exhibit favorable binding to the putative binding domain of USP14 with BE's of -9.8 and $-9.4 \mathrm{kcal} / \mathrm{mol}$, respectively (Table 3, Figure 6). In terms of binding mechanism, the chromanone core of dichamanetin (16) is affixed to the binding pocket through $p i$-anion interaction against Asp199 and stacked pi-amide bonding with Gln198. The hydroxybenzyl moiety, at the same time, is bound through $p i$-alkyl and stacked pi-pi attraction with Tyr476, Lys342, and Arg330. There are two prominent stacked pi-pi interactions responsible for compound 12's attachment to the binding site: (a) Phe331 with phenyl ring B of the hydroflavone moiety, and (b) Tyr476 and the benzyl group. Two hydroxyl substituents likewise formed hydrogen bonds with Gln198 and Asn340.

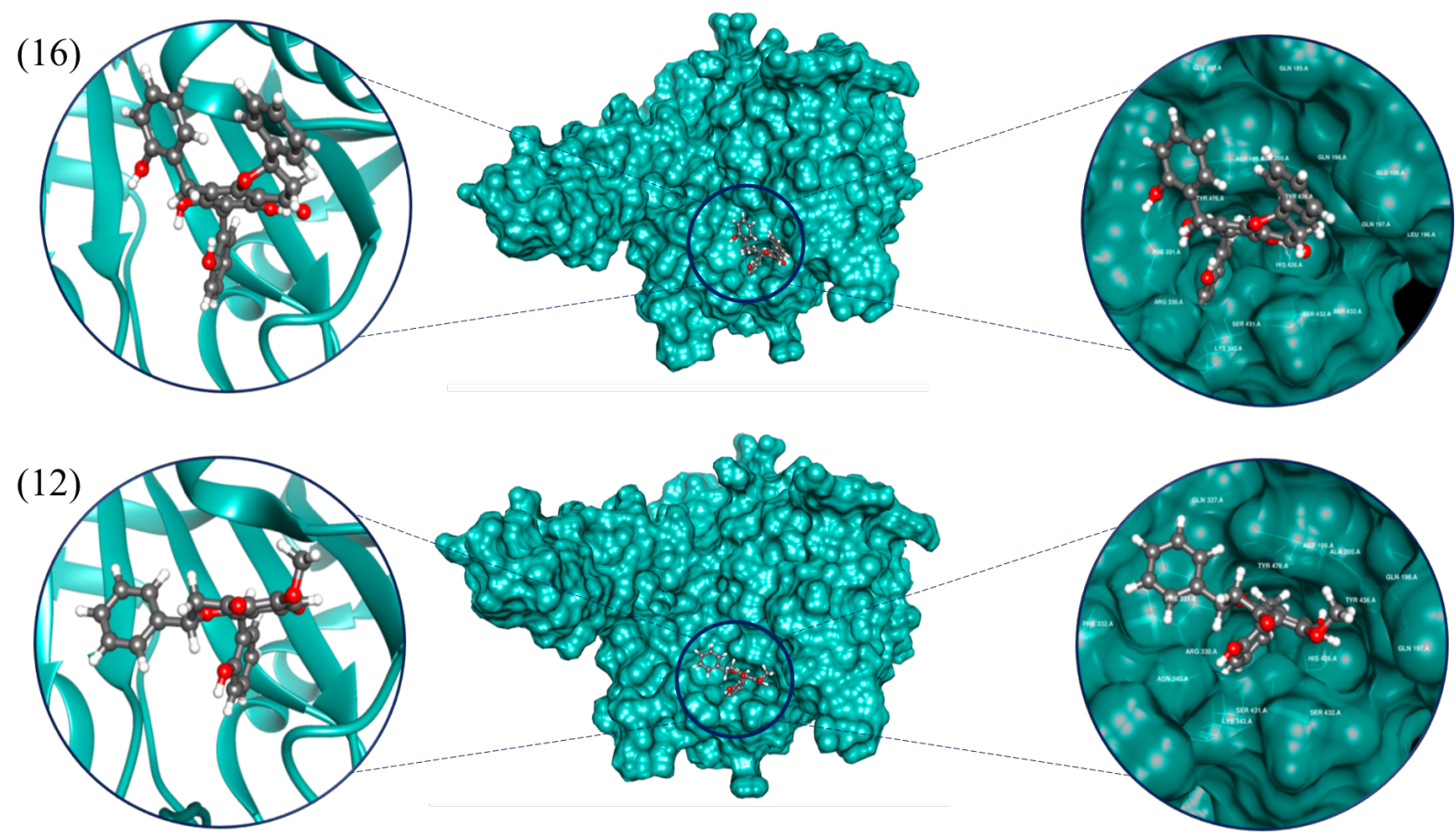

Figure 6. Docked poses of dichamanetin (16) and 5-O-methylchamanetin (12) against USP14 (PDB ID: 6IIM). 
Molecular docking was also performed in KEAP1 (Kelch-like ECH-associated protein 1). The structure of KEAP1, as with other BTB-Kelch proteins, is divided into four discrete domains: the $N$-terminal broad complex, Tramtrack and Bric-à-Brac (BTB) domain, a BACK domain, and a C-terminal Kelch domain [52]. The Kelch domain of the protein, showcasing a 6-bladed propeller-like structure, is required for substrate capture and can be the structural motifs of Nrf2 [53]. In the present study, we investigated the binding properties of the secondary metabolites to the Nrf2-binding region of the C-terminal Kelch domain of KEAP1. Of the secondary metabolites, dichamanetin (16) and cyathostemmine (13) conferred strong binding affinities to the said binding region of the protein with BE's of -11.1 and $-10.6 \mathrm{kcal} / \mathrm{mol}$, respectively (Table 3 , Figure 7 ). Dichamanetin's (16) attachment to the Kelch domain's active site is primarily through H-bonding with the ketone group of the chromanone core against Arg415 and the $\mathrm{OH}$ of two hydroxybenzyl substituents against Asn414 and Ile416. A distinct pi-sigma interaction between the chromanone core and Ala556 was also observed along with stacked pi-pi attraction between the phenyl substituent and Tyr572. For cyathostemmine (13), the complex was stabilized through polar pi affinities with the tyrosines of the Nrf2-binding region of the domain, specifically between (a) the xanthene core and Tyr 334 and (b) the two benzoyl groups against Tyr525 and Tyr572. In addition to that, $\mathbf{1 3}$ is further strengthened through H-bonding of two ester groups against Arg415 and Ser602. 


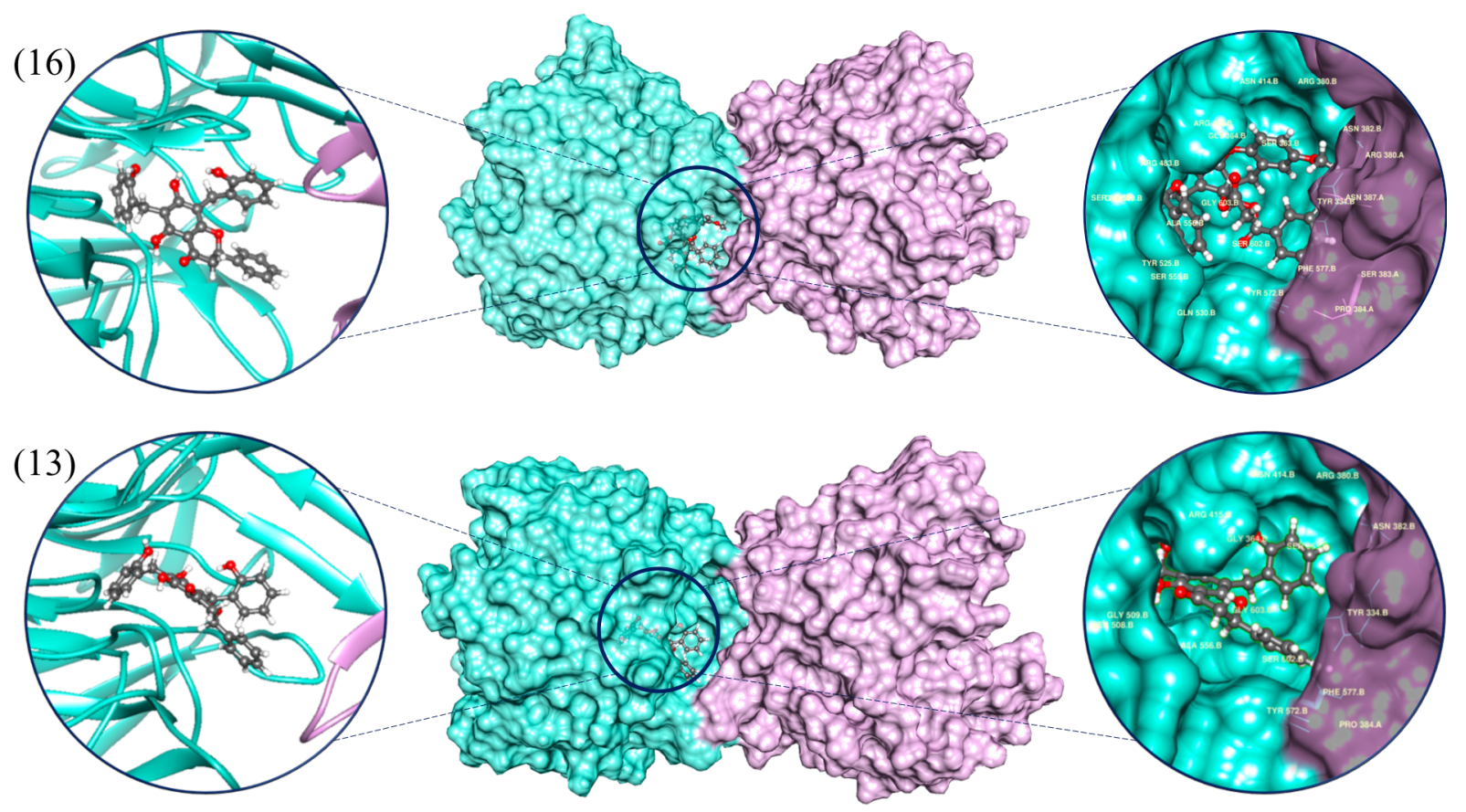

Figure 7. Docked poses of dichamanetin (16) and cyathostemmine (13) against KEAP1-Kelch domain (PDB ID: 47LB).

Another region of KEAP1 is the BTB domain, bearing the residue Cys 151 which is found to be a vital component for the post-translational modification of KEAP1 particularly upon exposure to oxidative stress [54]. Of note, grandifloracin (15) exhibited the highest affinity to the indicated binding region $(\mathrm{BE}=-7.3 \mathrm{kcal} / \mathrm{mol}$ ) (Table 3, Figure 8$)$. As observed in the post-dock analysis, compound 15 interacted with Cys151 through its tricyclododecenone core and one of the benzoyl substituents via pi-alkyl interplay. Several notable interactions include H-bonding and pication with Lys131, pi-sigma with His154, pi-pi stacking with His129, and alkyl interactions with Ala88, Pro89, and Pro130. Two other compounds showed significant binding to the BTB active region, namely valderramenol A (7) and 3-(3,4-dihydroxybenzyl)-3',4',6-trihydroxy-2,4dimethoxychalcone $(\mathbf{8})$, both with $\mathrm{BE}$ of $-7.1 \mathrm{kcal} / \mathrm{mol}$. In the case of compound 7 , Cys 151 
interacted via pi-alkyl with the compound's core and had caused a steric bump with a hydroxy substituent. Several stabilizing intermolecular forces were also observed such as pi-cation with Lys131, $p i$ stacking with His129, H-bonding with His154, and $p i$-alkyl interactions with Ala88 and $\operatorname{Arg} 135$. Compound $\mathbf{8}$, on the other hand, is hooked to Cys151 residue through pi-sulfur and $p i$-alkyl interactions with the B ring of the chalcone core and the phenol substituent, respectively. H-bonding with His154, $p i-p i$ stacking with Tyr85, and pi-alkyl interaction with Arg135 were observed between the compound and the active surface of the BTB domain.

(15)

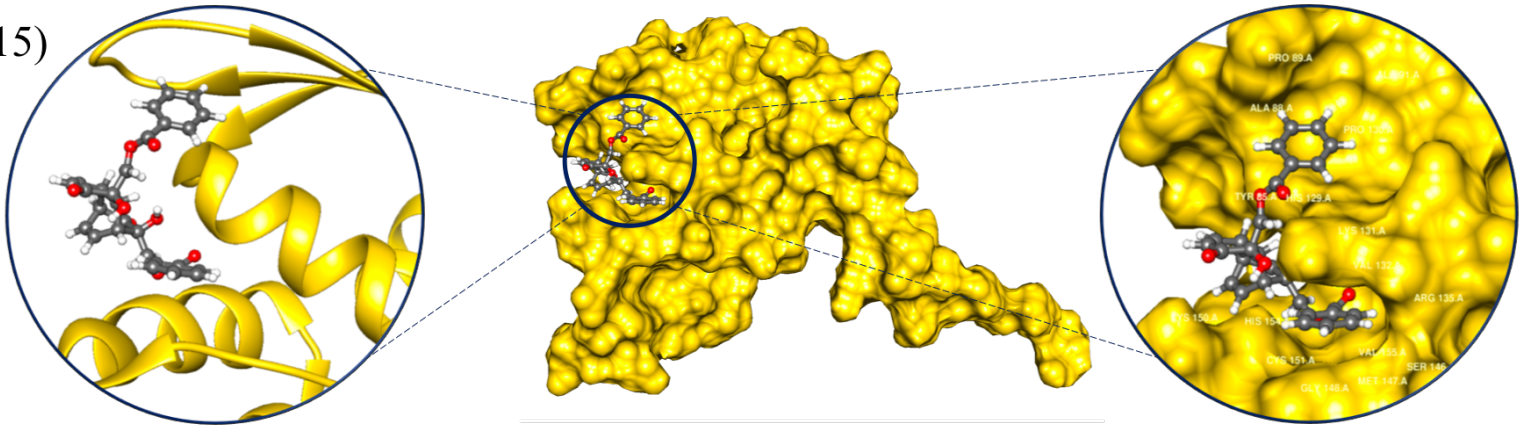

(7)

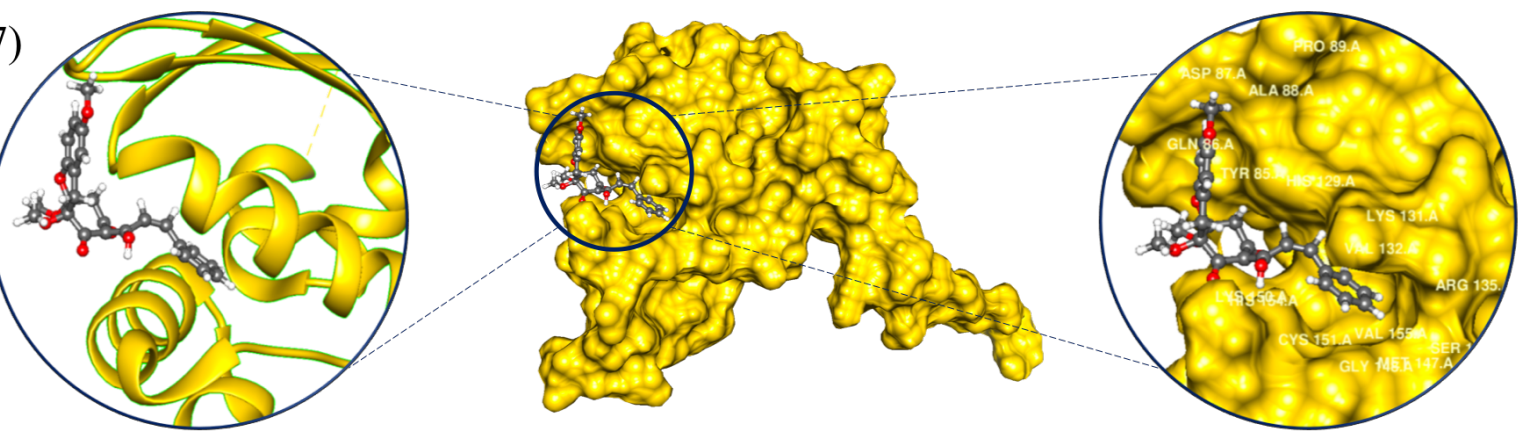

(8)

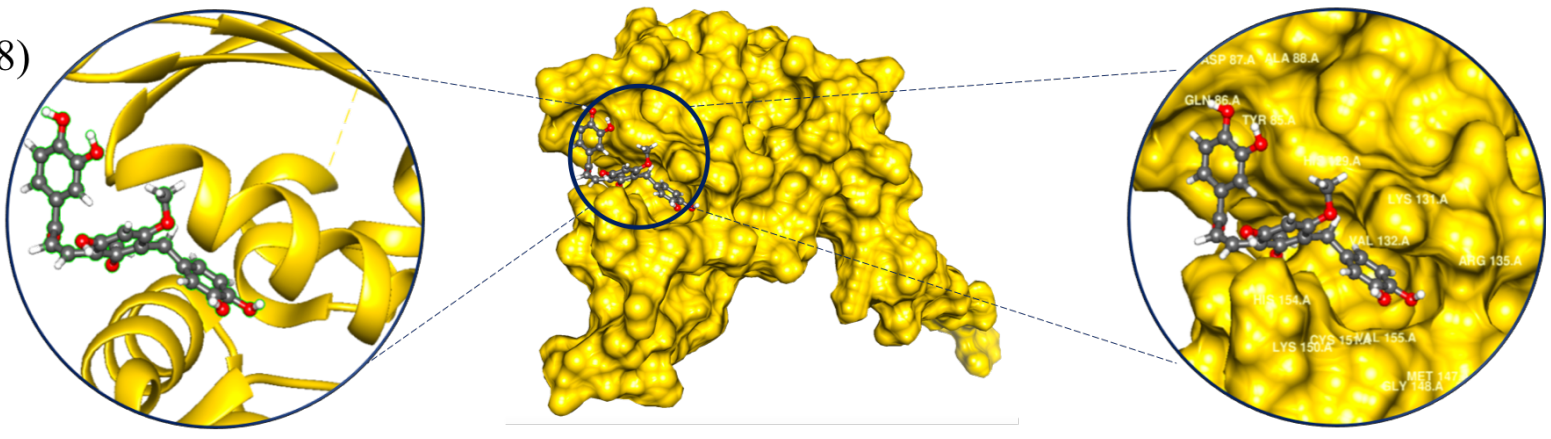


Figure 8. Docked poses of grandifloracin (16), valderammenol A (7), and 3-(3,4dihydroxybenzyl)-3',4',6-trihydroxy-2,4-dimethoxychalcone (8) against KEAP1-BTB domain (PDB ID: 5DAD).

\subsection{Molecular dynamics simulation of top-ranked ligands in complex with target enzymes}

The dynamics of the six ligand bound systems - 3-(3,4-dihydroxybenzyl)-3',4',6trihydroxy-2,4-dimethoxychalcone (8)-AChE, cyathostemmine (13)-PDE4 B2B, bractelactone (14)-PDE4 B2B, grandifloracin (15)-KEAP1 (BTB domain), dichamanetin (16)-KEAP1 (Kelch domain) and dichamanetin (16)-USP 14 - were found to be stable during the course of the molecular dynamics simulation at 50 ns (Figure 9). In the case of bractelactone (14)-PDE4 B2B, a minute fluctuation between 20 to $30 \mathrm{~ns}$ was noted. The system, however, remained stable for the rest of the time with an average root mean square deviation (RMSD) of $2.5 \AA$. On the other hand, the ligand cyathostemmine (13) bound to PDE4 B2B showed relatively high divergence at different intervals. The cyathostemmine (13)-PDE4 B2B complex showed major fluctuation initially from 8 to $26 \mathrm{~ns}$, however the system soon gained stability and no major fluctuation was observed thereafter. Overall the average RMSD of the complex was observed to be 3.5 to $4.0 \AA$. Between the two ligands, bractelactone (14) when bound to PDE4 B2B formed a more stable complex than cyathostemmine (13). In addition, the stability of 3-(3,4-dihydroxy benzyl)-3',4',6trihydroxy-2,4-dimethoxychalcone $(\mathbf{8})$ bound to AChE was also measured. The system was noted to be stable with an average RMSD of $1.5 \AA$. For this complex, an initial incremental increase in the RMSD of the ligand bound system was observed until $10 \mathrm{~ns}$ while for the rest of the simulation time the system attained stability. In the case of dichamanetin (16)-KEAP1 (Kelch domain), the system was found to be stable with a little convergence at 42 ns. Meanwhile, grandifloracin (15) in complex with the BTB domain of KEAP1 was noted to be stable throughout the simulation time 
with little convergence at 30 ns. Lastly, dichamanetin (16) in complex with USP 14 showed convergence at 10 to $15 \mathrm{~ns}$, while for the rest of the simulation time the system attained stability.
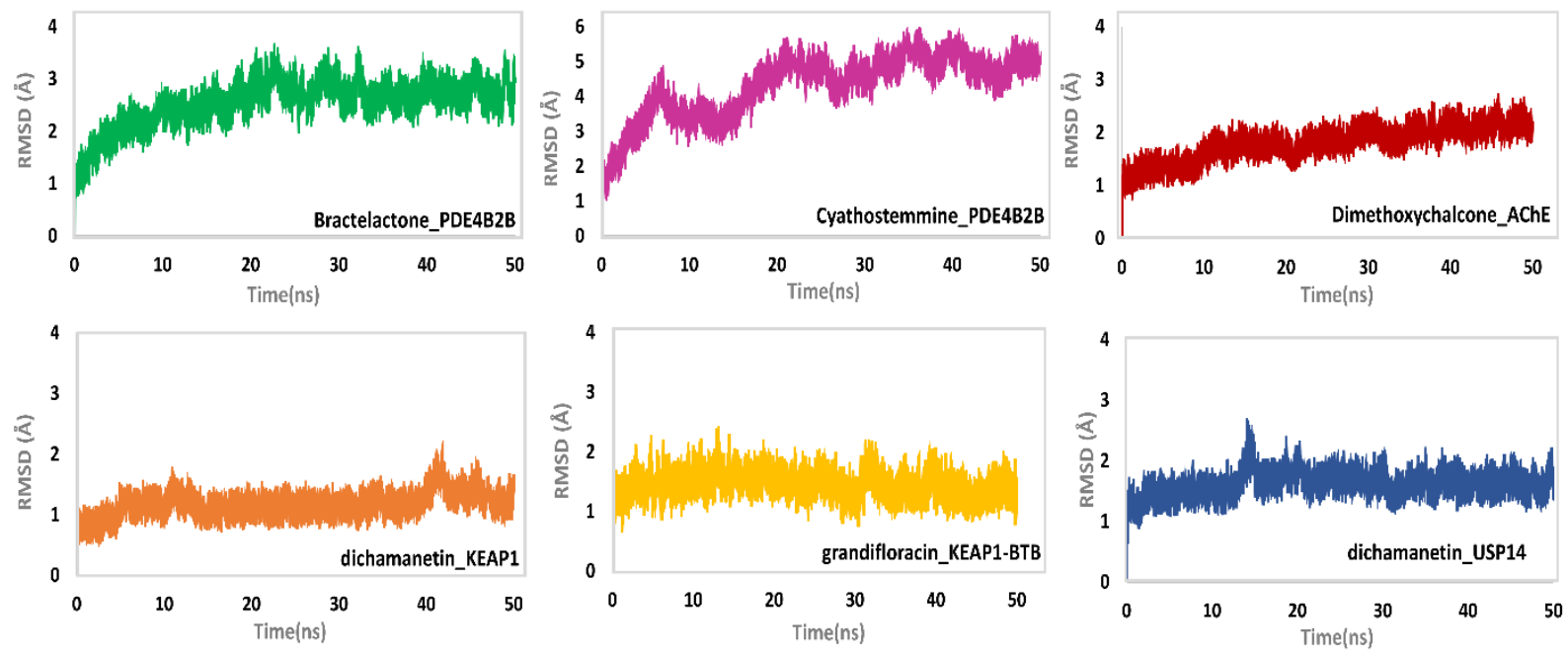

Figure 9. Root mean square deviation (RMSD, $\AA$ ) of top-scoring protein-ligand complexes as determined during 50-ns molecular dynamics simulation. The y-axis shows the RMSD value in $\AA$ while the $\mathrm{x}$-axis shows the time in nanoseconds.

Apart from calculating the RMSD, we also calculated the residual flexibility of each system (Figure 10). As shown, the cyathostemmine (13)-PDE4 B2B complex possessed more fluctuations than bractelactone (14) bound to the same enzyme. The major difference in the regions was detected at $80-90,140-150,210-220$ and significantly between 260-300. Thus, the binding of these different ligands to the same receptor differently affect the system's residual flexibility. The greater fluctuation in the cyathostemmine (13)-PDE4 B2B complex also justifies the relative unstable behavior noted during RMSD calculation. The average root mean square fluctuation (RMSF) for both complexes was reported to be between 2.0 to $2.5 \AA$. On the other hand, the average RMSF of 3-(3,4-dihydroxybenzyl)-3',4',6-trihydroxy-2,4- dimethoxychalcone (8) bound 
to AChE was observed to be 1 to $2.5 \AA$. A significant peak was also noted between $195-200$ residues in the said complex. For the dichamanetin (16)-KEAP1 (Kelch domain) complex, a higher fluctuation between 52-60 residues was noted, whereas grandifloracin (15) in complex with the BTB domain of KEAP1 showed a much higher fluctuation. The dichamanetin (16)-USP14 complex possessed an even higher fluctuation in the regions between 40-50, 120-130, 180-200, 220-230 and 255-260.
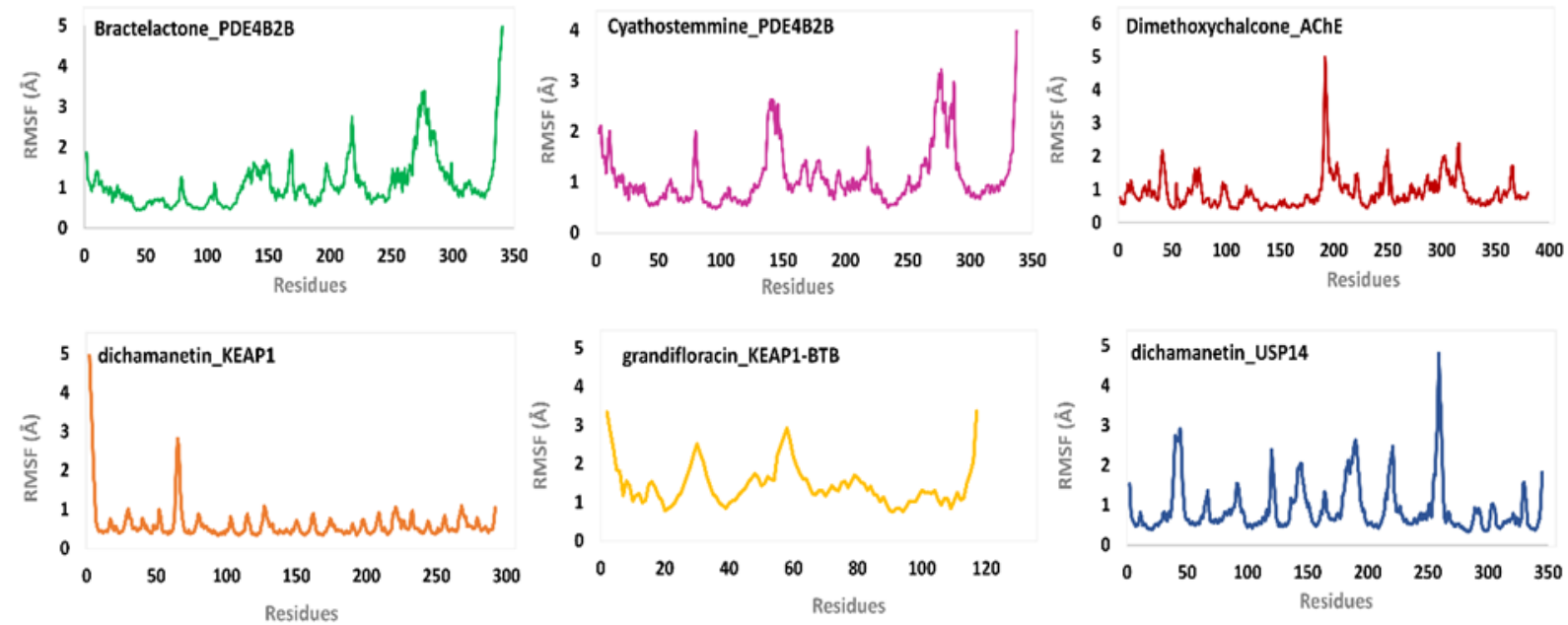

Figure 10. Root mean square fluctuation (RMSF) of selected top-scoring protein-ligand complexes. The x-axis shows the total residues while RMSF value in $\AA$ is given on y-axis.

\subsection{Assessing the radius of gyration of the top-ranked ligands in complex with target enzymes}

The cyathostemmine (13)-PDE4 B2B and bractelactone (14)-PDE4 B2B complexes possessed a similar pattern of compactness until $30 \mathrm{~ns}$ where there has been an increment increase in the radius of gyration $(\mathrm{Rg})$ of the cyathostemmine (13) bound to PDE4 B2B. Evidently, the said complex had lost compactness rising to as much as $21.2 \AA$ by the end of simulation. Meanwhile, 3-(3,4-dihydroxybenzyl)-3',4',6-trihydroxy-2,4-dimethoxychalcone (8) bound to AChE had an average $\operatorname{Rg}$ of $21.0 \AA$. Subsequently, the binding of grandifloracin (15) and dichamanetin (16) to the different binding domains of KEAP1 showed stable but different Rg patterns. The average $\mathrm{Rg}$ 
value for dichamanetin (16)-KEAP1 (Kelch) complex was reported to be $14 \AA$, while for grandifloracin (15) the Rg value was observed to be $18 \AA$. The higher $\mathrm{Rg}$ value for grandifloracin might be due to the higher fluctuation pattern observed in the RMSF of grandifloracin (15)-KEAP1 (BTB domain) system. In the case of dichamanetin (16)-USP14 complex, the average Rg value was observed to be $21.0 \AA$. Overall, the ligand bound systems possessed structural compactness favoring the tight binding of these ligands to their respective receptors (Figure 11).
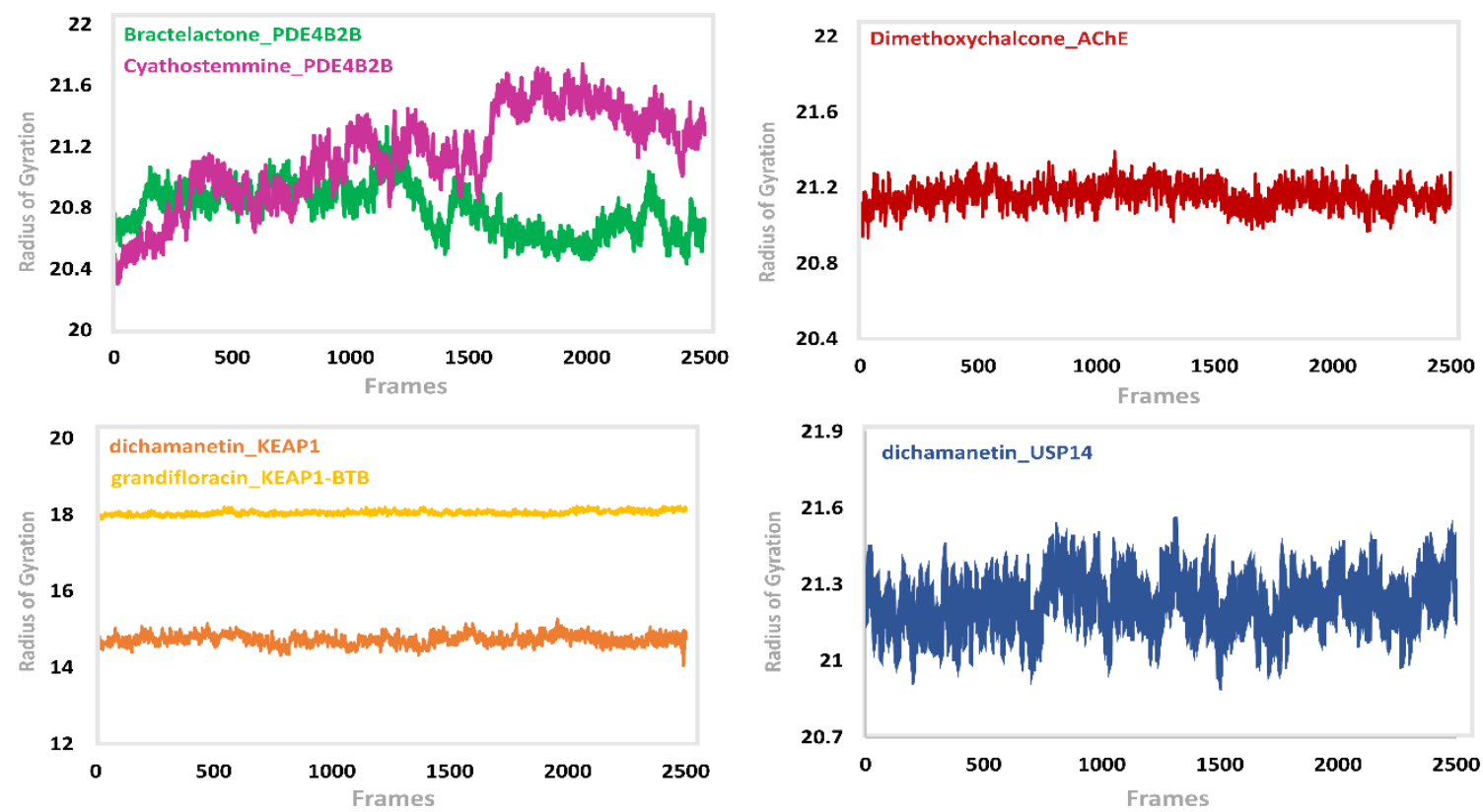

Figure 11. Radius of gyration of all the four ligands bound to different receptors. The y-axis shows the $\operatorname{Rg}$ value in $\AA$ while the $\mathrm{x}$-axis shows the frames.

\subsection{Binding free energy calculations}

The trajectories from molecular dynamics simulation were subjected to total binding free energy calculations. As shown (Table 4), the binding energy for bractelactone (14)-PDE4 B2B was reported to be $-66.64 \mathrm{kcal} / \mathrm{mol}$, while cyathostemmine (13), a different ligand binding to the same target, possessed a relatively less binding energy of $-65.11 \mathrm{kcal} / \mathrm{mol}$. The binding energies 
of these two ligands are comparatively very close to each other with no significant difference indicating that both compounds could efficiently inhibit PDE4 B2B. Furthermore, a relatively higher energy binding was detected for 3-(3,4-dihydroxybenzyl)-3',4',6- trihydroxy-2,4dimethoxychalcone (8) bound to the $\mathrm{AChE}$ receptor. The binding energy for this complex was at $-77.46 \mathrm{kcal} / \mathrm{mol}$ suggesting the strong inhibitory property of this compound to the AChE receptor. Meanwhile, for KEAP1, two of its binding domains were targeted. Dichamanetin (16) bound to the Kelch domain was found to have a binding energy of $-55.76 \mathrm{kcal} / \mathrm{mol}$, whereas grandifloracin (15) targeting the BTB domain was reported to have a total binding energy of $-48.41 \mathrm{kcal} / \mathrm{mol}$. On the other hand, dichamanetin (16) bound to USP14 possessed a very strong binding energy. The total binding energy for this system was observed to be $-83.98 \mathrm{kcal} / \mathrm{mol}$. The other energy terms such as vdW, electrostatic forces, polar solvation and solvent-accessible surface area (SASA) for each system that contributed to the total binding energy are given in Table 4.

Table 4. Binding energy (kcal/mol) results of the top scoring compounds $8,13,14,15$ and 16 .

\begin{tabular}{|c|c|c|c|c|c|}
\hline \multirow{2}{*}{ Complex Name } & \multicolumn{5}{|c|}{ MMGBSA } \\
\cline { 2 - 6 } & $\Delta \mathrm{vdW}$ & $\Delta \mathrm{elec}$ & $\Delta \mathrm{ps}$ & $\Delta$ SASA & $\Delta$ G Total \\
\hline $\begin{array}{c}\text { 3-(3,4-dihydroxy } \\
\text { benzyl)-3',4',6- } \\
\text { trihydroxy-2,4-di } \\
\text { methoxychalcone } \\
\text { (8)-AChE }\end{array}$ & -62.35 & -15.12 & 40.45 & -34.69 & -77.46 \\
\hline $\begin{array}{c}\text { cyathostemmine (13)- } \\
\text { PDE4 B2B }\end{array}$ & -62.72 & -2.39 & 33.63 & -36.26 & -65.11 \\
\hline $\begin{array}{c}\text { bractelactone (14)- } \\
\text { PDE4 B2B }\end{array}$ & -54.83 & -11.80 & 12.27 & -31.03 & -66.64 \\
\hline $\begin{array}{c}\text { grandifloracin (15)- } \\
\text { KEAP1 (BTB) }\end{array}$ & -54.37 & -8.21 & 22.24 & -29.14 & -48.41 \\
\hline $\begin{array}{c}\text { dichamanetin (16)- } \\
\text { KEAP1 (Kelch) }\end{array}$ & -50.57 & -5.19 & 30.02 & -27.68 & -55.76 \\
\hline $\begin{array}{c}\text { dichamanetin (16)- } \\
\text { USP14 }\end{array}$ & -66.60 & -17.38 & 37.30 & -31.94 & -83.98 \\
\hline
\end{tabular}

vdW = van der Waals energy; elec $=$ electrostatic energy; $\mathbf{p s}=$ polar solvation energy; SASA = solvent-accessible surface area energy; G Total = total binding free energy; MMGBSA = molecular mechanics generalized Born solvent accessibility 


\subsection{Frontier molecular orbital energy calculation of electrophilic U. alba metabolites}

The nucleophilic Cys151 residue of the BTB domain of KEAP1 has been considered as the main cysteine sensor for enone-bearing class of electrophilic inducers which upregulate cytoprotective responses and inhibit pro-inflammatory pathways of the enzyme. This nucleophilic residue is structurally positioned at the surface, and not on a deep pocket, making it available for a possible addition reaction, via covalent bond formation, with incoming electrophiles, aside from the usual intermolecular interactions predicted by molecular docking. Frontier orbitals HOMO and LUMO were used to calculate for the electrophilic potentials of the Michael acceptor enonebearing secondary metabolites of $U$. alba. Parr et al. introduced the concept of global electrophilicity index based from a compound's chemical potential and hardness, which are functions of the energetics of the molecular orbitals [39]. The HOMO-LUMO energies, hardness, chemical potential, and electrophilicity index are presented in Table 5 and Figure 12. The parameters were obtained by optimizing the target nucleophiles using B3LYP calculation via density functional theory. In the present study, 7-benzoyloxy-2H-1-benzopyran-2-one (1), grandifloracin (15) and valderramenol A (7) showed the highest electrophilicity indices among the metabolites. Of the three, however, grandifloracin (15) conferred the highest HOMO-LUMO band gap which suggests kinetic stability of the compound [55]. Based on molecular docking analysis, which is grounded on intermolecular forces, against the BTB domain of KEAP1, grandifloracin (15) and valderammenol A (7) were found to be the top binding ligands. Thus, we wish to further investigate the potentiality of a Michael addition reaction between these electrophilic metabolites and the nucleophilic Cys151 residue of the enzyme. 
Table 5. B3LYP/STO-3G electronic chemical potential $\boldsymbol{\mu}$, hardness $\boldsymbol{\eta}$ and global electrophilicity $\boldsymbol{\omega}$ of the electrophilic $U$. alba secondary metabolites.

\begin{tabular}{|c|c|c|c|}
\hline Compound & $\begin{array}{c}\text { chemical } \\
\text { potential, } \boldsymbol{\mu}(\mathbf{e V})\end{array}$ & hardness, $\boldsymbol{\eta}(\mathbf{e V})$ & $\begin{array}{c}\text { electrophilicity } \\
\text { index, } \boldsymbol{\omega}(\mathbf{e V})\end{array}$ \\
\hline $\mathbf{1}$ & -4.959722 & 7.24400 & 1.697877 \\
\hline $\mathbf{5}$ & -5.021220 & 7.67285 & 1.642978 \\
\hline $\mathbf{7}$ & -4.661211 & 6.49078 & 1.673672 \\
\hline $\mathbf{8}$ & -4.301746 & 6.14030 & 1.506850 \\
\hline $\mathbf{1 0}$ & -4.346917 & 6.54140 & 1.444316 \\
\hline $\mathbf{1 1}$ & -4.669647 & 6.51636 & 1.673142 \\
\hline $\mathbf{1 4}$ & -4.412225 & 5.90084 & 1.649574 \\
\hline $\mathbf{1 5}$ & -5.498920 & 8.96513 & 1.686429 \\
\hline $\mathbf{1 8}$ & -4.617672 & 6.68943 & 1.593776 \\
\hline
\end{tabular}

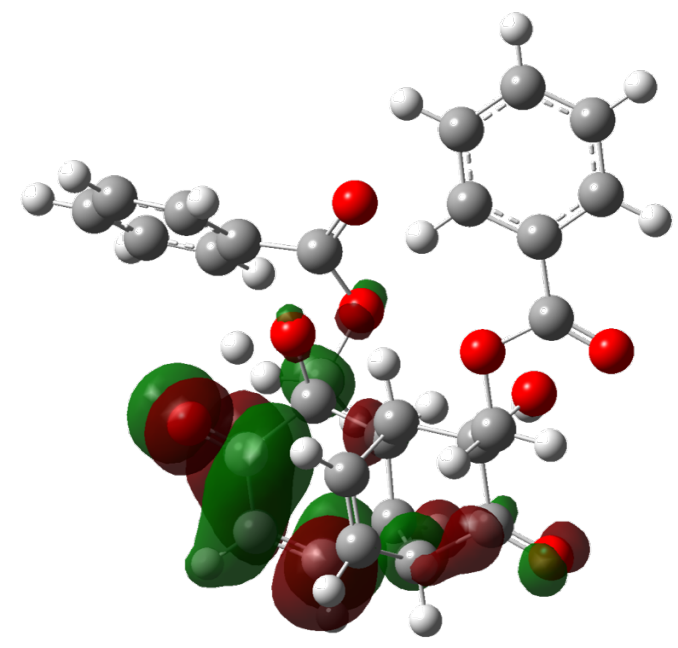

LUMO of electrophilic grandifloracin (15)

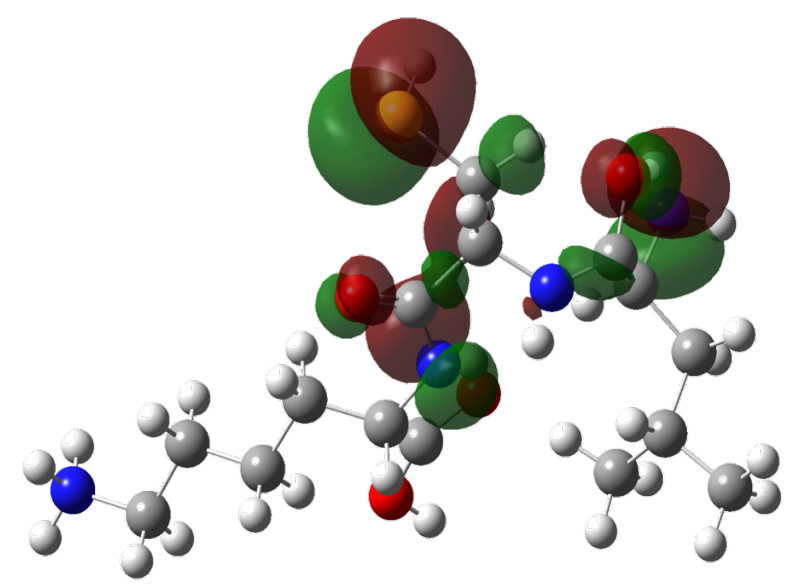

HOMO of nucleophilic Cys151-bearing tripeptide sequence (Lys-Cys-Val) of KEAP1

Figure 12. Frontier molecular orbitals of the grandifloracin (LUMO) and active nucleophilic residue of KEAP1 (HOMO) calculated at the B3LYP/STO-3G level of theory. 


\subsection{Reaction thermochemistry of the Michael addition of grandifloracin (15) and Cys 151}

$\alpha, \beta$-unsaturated carbonyl compounds have grown interest as drug candidates because of their ability to interact with heteroatomic nucleophiles of enzymes, such as the thiol group of cysteine residues, potentially through Michael addition [56]. Here, we wanted to explore the possibility of a covalent interaction, aside from the usual intermolecular interactions, between the electrophilic $U$. alba metabolites and the reactive cysteine residues of Keap1. One of the main considerations for exploiting Michael acceptor activity for the said enzyme is the presence of a highly reactive, easy-to-access thiol group, particularly from that of Cys151, found on the surface of the BTB domain of Keap1.

From among the $\alpha, \beta$-unsaturated-carbonyl-containing metabolites, grandilfloracin (15) was found to be the most electrophilic as per B3LYP/STO-3G frontier molecular orbital analysis, therefore 15 was used as the Michael acceptor to model the possible Michael addition between the U. alba metabolites and Cys151 of Keap1, represented as a truncated tripeptide (Lys150-Cys151Val152). The ground-state geometries of grandifloracin (15) and the tripeptide (19) were carried out using density functional theory at the $6-31 \mathrm{G}^{* *}(\mathrm{~d}, \mathrm{p})$ level of theory in aqueous medium (polarizable continuum model, PCM, solvent is water) to mimic biological conditions. Groundstate geometries are characterized though frequency calculation as those obtaining real frequencies only. The proposed mechanism involves the formation of an enol intermediate (20) through a concerted addition of a thiol group to the $\beta$-carbon of the $\alpha, \beta$-unsaturated ketone group of the Michael acceptor and a proton transfer to oxygen, followed by a keto-enol tautomerization to yield the final Cys151-grandifloracin keto adduct (21) (Scheme 1). 


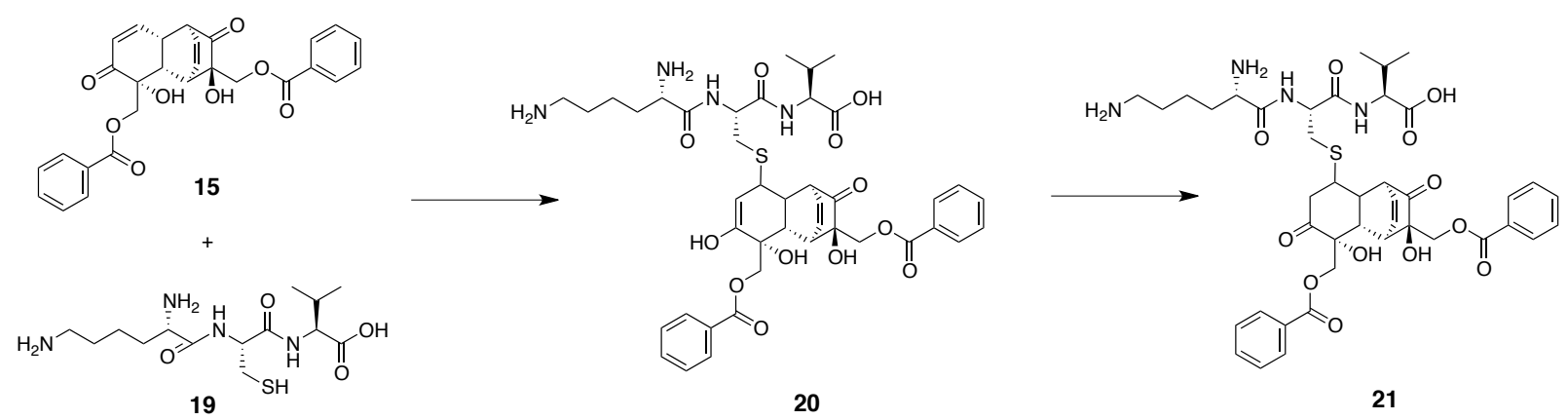

Scheme 1. Proposed Michael addition of grandifloracin (15) to the Cys 151 tripeptide segment (19) of the BTB domain of Keap1.

Transition state (TS) geometries were predicted using the QST3 method guided by the optimized geometries of two minima: the reactants and the intermediate/product. The TS was confirmed as having one, and only one, imaginary frequency (a negative vibrational eigenvalue) corresponding to the vibration along the reaction coordinate connecting the two minima. The geometry of the first transition state was searched by positioning the thiol group (S32) of Cys151 close to the $\beta$-carbon (C31) of grandifloracin (15) with an initial distance $\mathrm{r}_{\mathrm{s} \cdots \mathrm{C}}=2.50 \AA$ (Figure S22). The energy of activation of the reaction is defined as the energy difference, $\Delta \mathrm{E}^{\ddagger}$, of the first transition-state grandifloracin-Cys 151 adduct $\mathrm{E}^{\ddagger}$ and the ground-state $\mathrm{E}^{\mathrm{o}}$ of the reactants. This transition state proceeds toward the formation of the intermediate. The formation of the intermediate (grandifloracin-cys 151 enol adduct) is rate-determining $\left(\Delta \mathrm{E}^{\ddagger}=30.77 \mathrm{kcal} / \mathrm{mol}\right)$. The final step of the mechanism is keto-enol tautomerization, with $\Delta \mathrm{E}^{\dagger}{ }_{\mathrm{k}}$ eto-enol $=-20.02 \mathrm{kcal} / \mathrm{mol}$. As expected, the keto form of the adduct $\mathbf{2 1}$ (product) is more thermodynamically stable than the enol adduct (intermediate) 20. The reaction path and energetics of the Michael addition reaction between grandifloracin (15) and the Cys151-containing tripeptide (19) of the BTB domain of Keap1 is shown in Figure 13 and Table 6. 


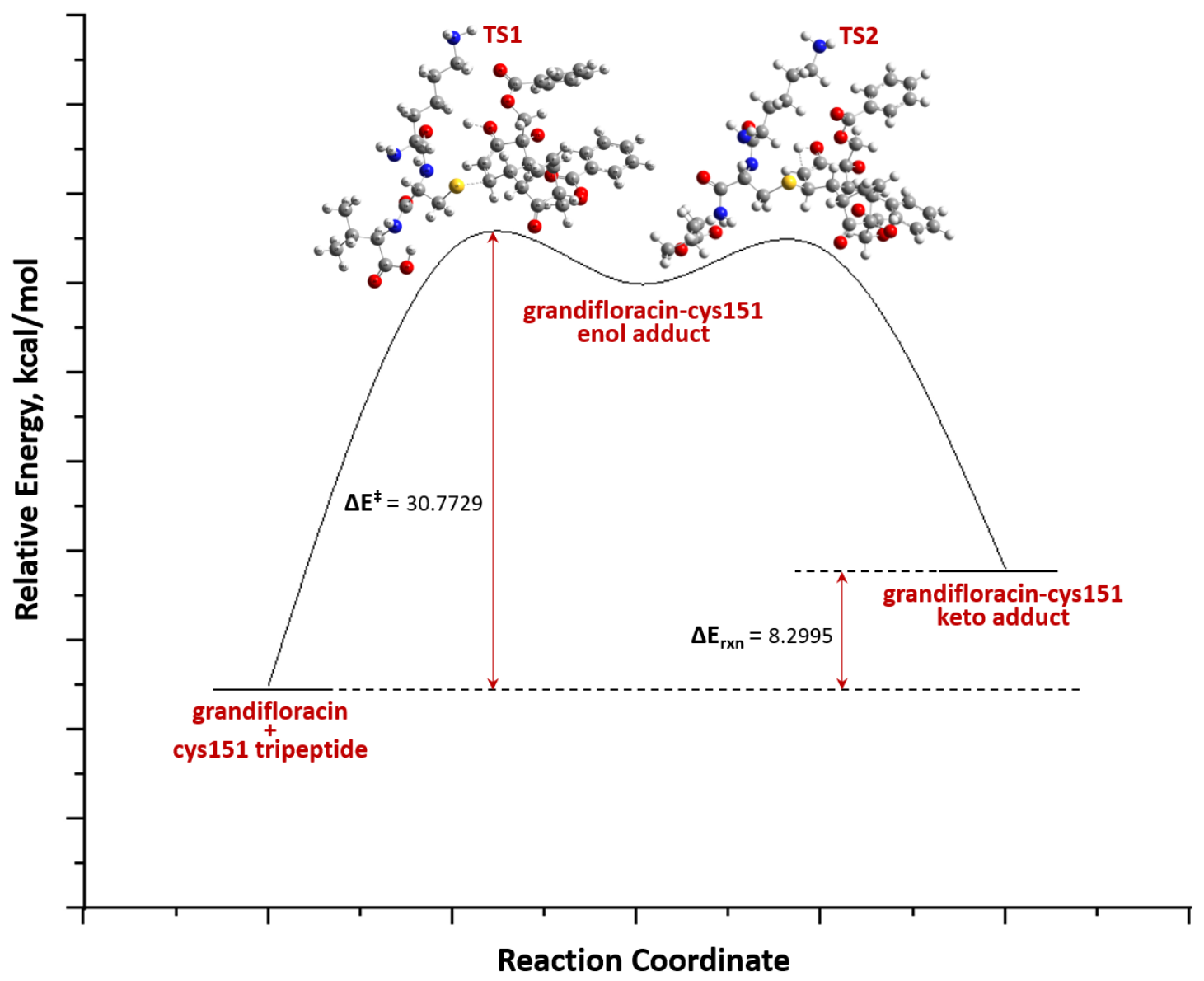

Figure 13. DFT/6-31G** $(\mathrm{d}, \mathrm{p})$ reaction profile of the Michael addition of grandifloracin (15) and Cys151 tripeptide (19) (Keap1-BTB domain). 
Table 6. Energetics of the reaction species calculated at the B3LYP/6-31G** level of theory with the PCM water solvation model.

\begin{tabular}{|c|c|c|}
\hline Reaction species & Energy, Ha & Relative Energy ${ }^{a}, \mathrm{kcal} / \mathrm{mol}$ \\
\hline reactants & -3151.815138 & - \\
\hline $\mathrm{TS} 1$ & -3151.766098 & 30.77 \\
\hline enol intermediate & -3151.770008 & 28.32 \\
\hline $\mathrm{TS} 2$ & -3151.766007 & 30.83 \\
\hline keto product & -3151.801912 & 8.30 \\
\hline \multicolumn{2}{|c|}{$\Delta E^{\ddagger}\left(E_{T S 1}^{\ddagger}-E_{\text {reactants }}^{\circ}\right)$} & 30.77 \\
\hline \multicolumn{2}{|c|}{$\Delta E_{\text {keto-enol }}^{\ddagger}\left(E_{\text {keto prod }}^{\circ}-E_{\text {enol intermediate }}^{\circ}\right)$} & -20.02 \\
\hline \multicolumn{2}{|c|}{$\Delta E_{\text {reaction }}^{\circ}\left(E_{\text {keto prod }}^{\circ}-E_{\text {reactants }}^{\circ}\right)$} & 8.30 \\
\hline
\end{tabular}

${ }^{\text {a }}$ relative to the reactants (grandifloracin + Cys151 tripeptide)

\subsection{Drug-likeness and ADMET prediction of secondary metabolites from UaD}

The overall pharmacokinetic behavior of the eighteen putative secondary compounds 1-18 identified in the dichloromethane sub-extract $(\mathrm{UaD})$ of $U$. alba was determined through in silico ADME (absorption, distribution, metabolism and excretion) screening. Basing the Lipinski's rule of five, the druggability of the compounds was predicted using the following descriptors: molecular weight, lipophilicity (reported as octanol-water partition coefficient), and the number of hydrogen bond donors and acceptors. Interestingly, all of the eighteen secondary metabolites including the top-ranked compounds such as 3-(3,4-dihydroxybenzyl)-3',4',6-trihydroxy-2,4dimethoxychalcone (8), cyathostemmine (13), bractelactone (14), grandifloracin (15) and dichamanetin (16) - exhibited good bioavailability and drug-likeness by fulfilling Lipinski's criteria (Table 7). Furthermore, the BOILED-Egg (brain or intestinal estimated permeation predictive model), an intuitive graphical plot of the functions of lipophilicity and apparent polarity, 
was used to predict passive intestinal absorption and brain permeation of the compounds (Figure 14). Compounds located in the yellow region (yolk) have a high probability of blood-brain barrier (BBB) penetration while those in the white region have the propensity for passive absorption through the gastrointestinal (GI) tract. Of note, compound $\mathbf{1 6}$ which demonstrated strong binding affinity to the target enzymes PDE4 B2B, USP14 and Keap1 (Kelch domain) was predicted to have good GI absorption and poor BBB crossing capacities. Likewise, compound 15 which showed favorable binding to Keap1 (BTB domain) shared the same pattern of bioavailability as dichamanetin (16). Despite having good binding affinity to AChE, compound $\mathbf{8}$ was predicted to be poorly absorbed in the GI tract hence explaining its location outside the white portion of the BOILED-egg model. A prediction of the toxicities, such as mutagenicity, tumorigenicity, irritant effect and reproductive toxicity, of the eighteen secondary metabolites from $U$. alba was also performed using OSIRIS Property Explorer (Table 8). Among the top-ranked compounds, 3-(3,4dihydroxybenzyl)-3',4',6-trihydroxy-2,4-dimethoxychalcone (8) did not demonstrate any form of toxicity. Grandifloracin (15), however, was found to demonstrate irritant effect, whereas dichamanetin (16) was predicted to confer tumorigenicity. Both compounds $\mathbf{1 5}$ and $\mathbf{1 6}$ were projected to induce reproductive toxicity. Thus, iteration of their structures is highly encouraged to improve their toxicity profile. 
Table 7. Lipinski's rule of five for ADME analysis of compounds 1-18.

\begin{tabular}{ccccccc}
\hline & \multicolumn{5}{c}{ Lipinski's Rule of Five } & \\
\cline { 2 - 5 } Compound & $\begin{array}{c}\text { Molecular weight } \\
\text { (g/mol) }\end{array}$ & $\begin{array}{c}\text { Lipophilicity } \\
\text { (MLogP) }\end{array}$ & $\begin{array}{c}\text { H- } \\
\text { bond } \\
\text { donors }\end{array}$ & $\begin{array}{c}\text { H-bond } \\
\text { acceptors }\end{array}$ & $\begin{array}{c}\text { Rule } \\
\text { violations }\end{array}$ & Drug-likeness \\
\cline { 2 - 5 } & $<500$ & $<5$ & $<5$ & $<10$ & $<2$ & \\
\hline $\mathbf{1}$ & 266.25 & 2.88 & 0 & 4 & 0 & yes \\
$\mathbf{2}$ & 408.40 & 2.62 & 0 & 7 & 0 & yes \\
$\mathbf{3}$ & 386.40 & 1.84 & 3 & 7 & 0 & yes \\
$\mathbf{4}$ & 386.40 & 1.84 & 3 & 7 & 0 & yes \\
$\mathbf{5}$ & 302.28 & 0.89 & 0 & 6 & 0 & yes \\
$\mathbf{6}$ & 310.34 & 3.83 & 0 & 4 & 0 & yes \\
$\mathbf{7}$ & 436.45 & 1.00 & 1 & 7 & 0 & yes \\
$\mathbf{8}$ & 438.43 & 1.26 & 5 & 8 & 1 & yes \\
$\mathbf{9}$ & 446.88 & 3.22 & 1 & 7 & 0 & yes \\
$\mathbf{1 0}$ & 314.33 & 1.75 & 1 & 5 & 0 & yes \\
$\mathbf{1 1}$ & 422.43 & 0.80 & 2 & 7 & 0 & yes \\
$\mathbf{1 2}$ & 376.40 & 2.33 & 2 & 5 & 0 & yes \\
$\mathbf{1 3}$ & 528.55 & 3.75 & 0 & 8 & 1 & yes \\
$\mathbf{1 4}$ & 416.42 & 2.60 & 2 & 6 & 0 & yes \\
$\mathbf{1 5}$ & 488.49 & 1.89 & 2 & 8 & 0 & yes \\
$\mathbf{1 6}$ & 468.50 & 2.79 & 4 & 6 & 0 & yes \\
$\mathbf{1 7}$ & 390.86 & 2.66 & 2 & 5 & 0 & yes \\
$\mathbf{1 8}$ & 436.45 & 1.00 & 1 & 7 & 0 & yes \\
\hline & & & & & &
\end{tabular}




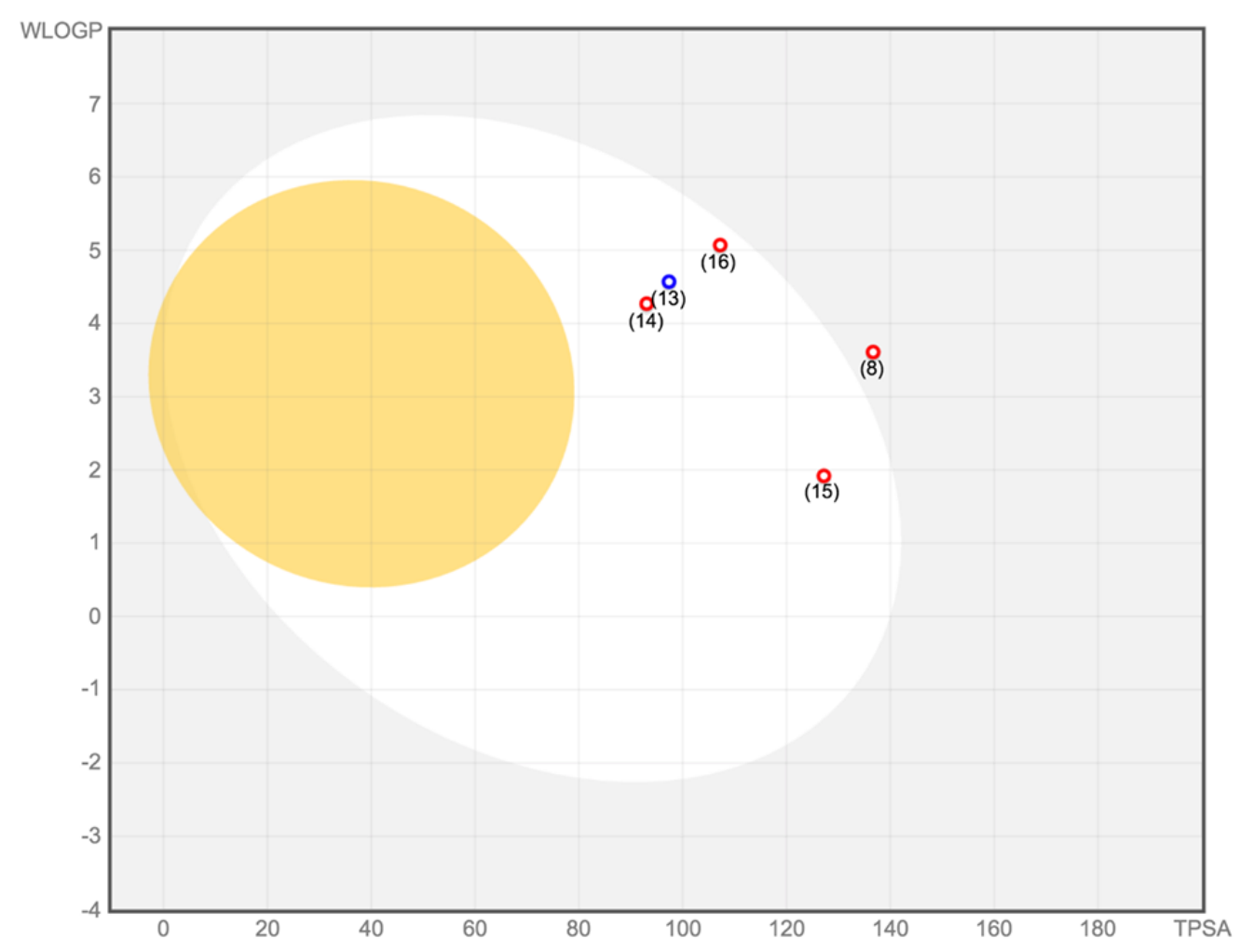

Figure 14. Prediction of gastrointestinal (GI) tract and brain permeation of the top-ranked Uvaria alba secondary metabolites - 3-(3,4-dihydroxybenzyl)-3',4',6-trihydroxy-2,4-dimethoxychal cone (8), cyathostemmine (13), bractelactone (14), grandifloracin (15) and dichamanetin (16) - by brain or intestinal estimated permeation predictive model (BOILED-Egg) method.

Table 8. Predicted toxicity parameters of compounds 1-18.

\begin{tabular}{|c|c|c|c|c|}
\hline Compound & Mutagenicity & Tumorigenicity & Irritant Effect & $\begin{array}{c}\text { Reproductive } \\
\text { Toxicity }\end{array}$ \\
\hline $\mathbf{1}$ & None & None & None & High Risk \\
\hline $\mathbf{2}$ & None & None & None & High Risk \\
\hline $\mathbf{3}$ & None & None & High Risk & Medium Risk \\
\hline $\mathbf{4}$ & None & None & High Risk & Medium Risk \\
\hline $\mathbf{5}$ & None & None & High Risk & None \\
\hline
\end{tabular}




\begin{tabular}{|c|c|c|c|c|}
\hline $\mathbf{6}$ & None & None & High Risk & None \\
\hline $\mathbf{7}$ & None & None & None & None \\
\hline $\mathbf{8}$ & None & None & None & None \\
\hline $\mathbf{9}$ & None & None & High Risk & High Risk \\
\hline $\mathbf{1 0}$ & None & None & None & None \\
\hline $\mathbf{1 1}$ & None & None & None & None \\
\hline $\mathbf{1 2}$ & None & Medium Risk & None & Medium Risk \\
\hline $\mathbf{1 3}$ & None & None & High Risk & None \\
\hline $\mathbf{1 4}$ & None & None & None & High Risk \\
\hline $\mathbf{1 5}$ & None & None & High Risk & Medium Risk \\
\hline $\mathbf{1 6}$ & None & Medium Risk & None & Medium Risk \\
\hline $\mathbf{1 7}$ & None & None & High Risk & High Risk \\
\hline $\mathbf{1 8}$ & None & None & None & None \\
\hline
\end{tabular}

\section{Discussion}

The search for new sources of drugs for cancer and neurodegenerative diseases remains a challenge, especially with the complexity of their pathophysiological mechanisms. With the pharmaceutical successes of plant-based metabolites, such as the anti-tumor drug paclitaxel and the acetylcholinesterase inhibitor galantamine, natural products research has been the basis of discovering new drugs that can be used to treat several diseases, including cancer and Alzheimer's diseases [7, 57]. The genus Uvaria, in particular, is valued for its ethnopharmacological use containing metabolites with structural novelty and a wide array of pharmacological activities, such as anticancer, anti-infective and anti-inflammatory. Of interest is the endemic Uvaria alba on which few studies described its biological activities and phytochemistry. In this study, the DCM sub-extract of $U$. alba leaves showed antiproliferative activity against K-562 and cytostatic activity 
against HeLa cells. Likewise, the DCM sub-extract exhibited AChE and PDE4 B2 inhibitory activities.

PDE4 B2 is known to participate in signal transduction by regulating the cellular concentrations of cyclic nucleotides [2]. It is normally expressed in many tissue types. For example, PDE4 B2 was upregulated in colorectal cancer (CRC) with oncogenic $K R A S$ thereby inhibiting apoptosis and disrupting cell polarity [58]. Thus, PDE4 B2 is an attractive therapeutic target for $\mathrm{CRC}$ as exemplified by the mechanism of action of apremilast, a known PDE4 B inhibitor. In a previous study, apremilast induced apoptosis in a three-dimensional culture of CRC [59]. Interestingly, UaD inhibited PDE4 B2 indicating potential for further testing against CRC with KRAS mutation. Furthermore, downregulation of PDE4 B2 has also been implicated with neuronal plasticity and pro-cognitive development, thus $\mathrm{UaD}$, an inhibitor of this enzyme, may also have neuroprotective effects. This claim is further strengthened in our result showing that $\mathrm{UaD}$ inhibited $\mathrm{AChE}$ - an enzyme responsible for terminating nerve impulse transmission at the cholinergic synapses by rapid hydrolysis of acetylcholine. Similar to PDE4 B2, inhibition of AChE is recognized as a strategy for treating Alzheimer's and Parkinson's diseases [6]. Thus, UaD may confer neuroprotective effects by modulating the activity of PDE4 B2 and AChE.

To further investigate the therapeutic potentials of $U$. alba, eighteen secondary metabolites, identified through LC-HR-ESIMS-QToF analysis, were subjected to in silico experiments to corroborate the observed anti-antiproliferative, anticholinesterase and anti-phosphodiesterase inhibitory activities of the extracts. Molecular docking was performed to determine the affinity of the $U$. alba secondary metabolites to the enzyme targets PDE4 B2B and AChE vital for inflammation and neuronal degeneration, and to ubiquitin specific peptidase 14 (USP14) and Kelch-like ECH-associated protein 1 (KEAP1) essential for cancer growth and development. 
In this study, it was demonstrated that the aromatic metabolites showed the highest binding affinities against PDE4 B2B (dichamanetin (16) and grandifloracin (15)) and AChE (3-(3,4dihydroxybenzyl)-3',4',6-trihydroxy-2,4-dimethoxychalcone (8) and bractelactone (14)). Hence, these compounds may be responsible for the purported anticholinesterase and antiphosphodiesterase activities of the $\mathrm{UaD}$ sub-extract.

USP14, a member of the deubiquitinating enzymes, is another important potential drug target due to its involvement in cancer development and neurodegenerative diseases. Here, molecular docking analysis revealed two benzylated hydroxyflavones, dichamanetin (16) and 5$O$-methylchamanetin (12) which showed high binding affinities against USP14. Regulation of the ubiquitin-proteasome system is an essential control mechanism and potential inhibitors of DUBs, including USP14, thus, may balance and prevent disruption of this regulatory system.

Keap1, which is a member of the BTB-Kelch family of proteins, is known to interact with Nrf2 (nuclear factor erythroid 2) [60,61]. Activation with Nrf2 leads to a coordinated antioxidant and anti-inflammatory response of the enzyme. There are two distinct regions of Keap1 that we studied as potential targets: the C-terminal Kelch domain and BTB domain. The KEAP1-Kelch domain acts as the receptor for Nrf2. Molecular docking at the Kelch domain gave two potential inhibitors: dichamanetin (16) and cyathostemmine (13). Another important region of Keap1 is the central BTB domain, particularly for its role in providing sensing mechanisms to oxidative stress. This domain houses the nucleophilic residue, Cys151, which was found to be one of the most reactive residues in the regulation of cellular stress $[62,63]$. Thus, the docking behavior of the secondary metabolites was tested against the BTB domain of the enzyme, particularly directed in and around Cys151. Interestingly, the three top-scoring metabolites - grandifloracin (15), valderramenol A (7) and 3-(3,4-dihydroxybenzyl)-3',4',6-trihydroxy-2,4-dimethoxychalcone (8) 
- are enone-bearing Michael acceptors. While these compounds interacted with Cys151 via significant intermolecular forces of attraction, we speculate that a possible Michael addition may occur between the electrophilic metabolites and the nucleophilic Cys151 residue. The nucleophilic Cys151 residue of the BTB domain of KEAP1 has been considered as the main cysteine sensor for enone-bearing class of electrophilic inducers which upregulate cytoprotective responses and inhibit pro-inflammatory pathways of the enzyme. This nucleophilic residue is structurally positioned at the surface, and not on a deep pocket, making it available for a possible addition reaction, via covalent bond formation, with incoming electrophiles, aside from the usual intermolecular interactions predicted by molecular docking.

U. alba metabolites that bear $\alpha, \beta$-unsaturated carbonyl groups, were assessed for their electrophilicity indices based on frontier molecular orbital analysis. This index can be used to do an empirical rank-based assessment of the electrophilic nature of the metabolites as they possibly undergo Michael addition reaction with the active nucleophilic residue of the BTB domain of KEAP1, Cys151. Grandifloracin (15), being one of the most electrophilic metabolites and having the highest kinetic stability, was chosen to demonstrate the potentiality of a Michael addition reaction between the electrophilic metabolites with the truncated Cys151 tripeptide of BTB domain through density functional theory calculations. The reaction proceeds via a concerted ratedetermining endothermic grandifloracin-Cys151 enol adduct formation, followed by an exothermic keto-enol tautomerization. Unlike most conjugate addition reactions, the initial ratedetermining step is endothermic probably due to steric interactions of the bulky grandifloracin structure with the tripeptide, which means that steric accessibility of the reactant could be a major driving force for the feasibility of the reaction. A similar finding was also observed with the Michael addition of deoxyguanosine to catechol estrogen-3,4-quinone [64] and the aza-Michael 
addition of Lys16 (of $\beta$-amyloid A $\beta 42$ fibrils) to oxidized (+)-taxifolin [65], wherein the formation of the enol adduct is endothermic.

The top-ranked complexes for each enzyme, based on molecular docking, were subjected to a 50-ns molecular dynamics simulation. RMSD analysis revealed that the ligand-bound systems of the top-ranked complexes attained dynamic stability. These systems likewise exhibited structural compactness favoring tight binding of the ligands to their respective receptors. Furthermore, the computed total binding free energy of these complexes using MMPBSA approach provides credence to the strong binding capacity of the ligands to their respective target receptors.

Lastly, the pharmacokinetics of the $U$. alba secondary metabolites were predicted via assessment of their ADMET (absorption, distribution, metabolism, excretion and toxicity) profiles in silico. Interestingly, all tested metabolites conferred with the Lipinski's rule of 5, which suggests good bioavailability and drug-likeness.

\section{Conclusion}

The dichloromethane sub-extract of Uvaria alba (UaD) showed antiproliferative, anticholinesterase and anti-phosphodiesterase properties in vitro. Eighteen putative secondary compounds were detected in the LC-HR-ESIMS-QToF spectra of UaD. In silico target fishing identified dichamenetin (16) to have strong binding affinities to PDE4 B2B, USP14 and KEAP1Kelch domain. Furthermore, 3-(3,4-dihydroxybenzyl)-3',4',6-trihydroxy-2,4-dimethoxychalcone (8) and grandifloracin (15) demonstrated favorable binding to AChE and KEAP1-BTB domain, respectively. Molecular dynamics simulation revealed that the complexes formed between the topranked ligands and their protein targets are dynamically stable. This is the first report highlighting 
the potential of $U$. alba to synthesize compounds with anticholinesterase and antiphosphodiesterase properties. This is also the first study to demonstrate the potential of grandifloracin (15) to initiate a Michael addition reaction with the active nucleophilic Cys151containing tripeptide in the Keap1-BTB domain. With favorable pharmacokinetic properties of top-ranked ligands, these results suggest further investigations on the secondary metabolites of $U$.

$a l b a$ against their respective target proteins for the discovery of new drug leads against cancer and $\mathrm{AD}$.

\section{Funding}

This work was supported in part by the International Foundation for Science (Grant no. F/53761).

\section{Conflict of interests}

The authors declare that they have no conflict of interests.

\section{References}

1. Y. Yamanaka, T. Mammoto, T. Kirita, M. Mukai, T. Mashimo, M. Sugimura, Y. Kishi, H. Nakamura, Epinephrine inhibits invasion of oral squamous carcinoma cells by modulating intracellular cAMP. Cancer Lett. 176 (2002) 143-148. DOI:10.1016/s0304$3835(01) 00764-9$.

2. L. Zhang, F. Murray, A. Zahno, J.R. Kanter, D. Chou, R. Suda, M. Fenlon, L. Rassenti, H. Cottam, T.J. Kipps, P.A. Insel, Cyclic nucleotide phosphodiesterase profiling reveals increased expression of phosphodiesterase 7B in chronic lymphocytic leukemia. Proc. Natl. Acad. Sci. USA 105 (2008) 19532-19537. DOI:10.1073/pnas.080615210. 
3. K Omori, J. Kotera, Overview of PDEs and their regulation. Circ. Res. 100 (2007) 309327. DOI:10.1161/01.RES.0000256354.95791.f1.

4. S.S. Pullamsetti, G.A. Banat, A. Schmall, M. Szibor, D. Pomagruk, J. Hänze, E. Kolosionek, J. Wilhelm, T. Braun, F. Grimminger, W. Seeger, Phosphodiesterase-4 promotes proliferation and angiogenesis of lung cancer by crosstalk with HIF. Oncogene 2(9) (2013) 1121-1134. DOI:10.1038/onc.2012.136.

5. P.R. Heckman, C. Wouters, J. Prickaerts, Phosphodiesterase inhibitors as a target for cognition enhancement in aging and Alzheimer's disease: A translational overview. Curr. Pharm. Design 21(3) (2015) 317-331. DOI:10.2174/1381612820666140826114601.

6. L.B. Roseiro, A.P. Rauter, M.L. Serralheiro, Polyphenols as acetylcholinesterase inhibitors: Structural specificity and impact on human disease. Nutr. Aging 1(2) (2012) 99-111. DOI:10.3233/NUA-2012-0006.

7. A. Dey, R. Bhattacharya, A. Mukherjee, D.K. Pandey, Natural products against Alzheimer's disease: Pharmacotherapeutics and biotechnological interventions. Biotech. Adv. 35(2) (2017) 178-216. DOI:10.1016/j.biotechadv.2016.12.005.

8. N. Okimoto, N. Futatsugi, H. Fuji, A. Suenaga, G. Morimoto, R. Yanai, Y. Ohno, T. Narumi, M. Taiji, High-performance drug discovery: Computational screening by combining docking and molecular dynamics simulations. PLoS Comp. Biol. 5(10) (2009) e1000528. DOI:10.1371/journal.pcbi.1000528.

9. D. Chen, P.Q. Dou, The ubiquitin-proteasome system as a prospective molecular target for cancer treatment and prevention. Curr. Protein Pept. Sci. 11(6) (2010) 459-470. DOI: $10.2174 / 138920310791824057$. 
10. K. Selvaraju, A. Mofers, P. Pellegrini, J. Salomonsson, A. Ahlner, V. Morad, E.K. Hillert, B. Espinosa, E.S. Arnér, L. Jensen, J. Malmström, Cytotoxic unsaturated electrophilic compounds commonly target the ubiquitin proteasome system. Sci. Rep. 9(1) (2019) 1-17. DOI:10.1038/s41598-019-46168-x.

11. S. Sajadimajd, M. Khazaei, Oxidative stress and cancer: The role of Nrf2. Curr. Cancer Drug Targets 18(6) (2018) 538-557. DOI:10.2174/1568009617666171002144228.

12. I.M. Copple, The Keap1-Nrf2 cell defense pathway - A promising therapeutic target? Adv. Pharmacol. 63 (2012) 43-79. DOI:10.1016/B978-0-12-398339-8.00002-1.

13. M. Bello, M.J.A. González, Molecular recognition between potential natural inhibitors of the Keap1-Nrf2 complex. Int. J. Biol. Macromol. 105 (2017) 981-992. DOI:10.1016/j.ijbiomac. 2017.07.117.

14. F.A. Tudla, A.M. Aguinaldo, H. Hussain, K. Krohn, A.P.G. Macabeo, Highly oxygenated cyclohexene metabolites from Uvaria rufa. Biochem. Syst. Ecol. 35 (2007) 45-47. DOI:10. 1016/j.bse.2006.08.006.

15. K.I.R. Notarte, M.K.P. Devanadera, A.B.R. Mayor, M.C.A. Cada, M.H. Pecundo, A.P.G. Macabeo, Toxicity, antibacterial and antioxidant activities of fungal endophytes Colletotrichum and Nigrospora spp. isolated from Uvaria grandiflora. Phil. J. Sci. 148(3) (2019) 505-512.

16. A.P.G. Macabeo, A.D.A. Lopez, S. Schmidt, J. Heilmann, H.M. Dahse, G.J.D. Alejandro, S.G. Franzblau, Antitubercular and cytotoxic constituents from Goniothalamus gitingensis, Rec. Nat. Prod. 8 (2014) 41-45. 
17. A.P.G. Macabeo, A.G. Letada, S. Budde, C. Faderl, H.M. Dahse, S.G. Franzblau, G.J.D. Alejandro, G.K. Pierens, M.J. Garson, Antitubercular and cytotoxic chlorinated secocyclohexenes from Uvaria alba. J. Nat. Prod. 80(12) (2017) 3319-3323. DOI:10.1021/ acs.jnatprod.7b00679.

18. A.P.G. Macabeo, A.I.G. Flores, R.A.T. Fernandez, S. Budde, C. Faderl, H.M. Dahse, S.G. Franzblau, Antitubercular and cytotoxic polyoxygenated cyclohexane derivatives from Uvaria grandiflora. Nat. Prod. Res. (2020) 1-4. DOI:10.1080/14786419.2020.1741579.

19. A.P.G. Macabeo, F.A. Tudla, G.J.D. Alejandro, S.F. Kouam, H. Hussain, K. Krohn, Benzoylated derivatives from Uvaria rufa. Biochem. Syst. Ecol. 38(4) (2010) 857-860. DOI:10.1016/j.bse.2010.08.007.

20. A.P.G. Macabeo, F.P.A. Martinez, T. Kurtan, L. Toth, A. Mandi, S. Schmidt, J. Heilmann, G.J.D. Alejandro, M. Knorn, H.M. Dahse, S.G. Franzblau, Tetrahydroxanthene-1,3(2H)dione derivatives from Uvaria valderramensis. J. Nat. Prod. 77(12) (2014) 2711-2715. DOI:10.1021/np500538c.

21. A.P.G. Macabeo, L.A.E. Pilapil, K.Y.M. Garcia, M.T.J. Quimque, C. Phukhamsakda, A.J.C. Cruz, K.D. Hyde, M. Stadler, Alpha-glucosidase and lipase-inhibitory phenalenones from a new species of Pseudolophiostoma originating from Thailand. Molecules 25(4) (2020) 965-973. DOI:10.3390/molecules25040965.

22. F. Krauth, H.M. Dahse, H.H. Rüttinger, P. Frohberg, Synthesis and characterization of novel 1,2,4-triazine derivatives with antiproliferative activity. Bioorg. Med. Chem. 18(5) (2010) 1816-1821. DOI:10.1016/j.bmc.2010.01.053.

23. L.E.C. Luz, C.C. Kanunfre, K.S. Paludo, A. da Silva Justo, V.K. Petry, B.M. Lemes, A. Barison, A. Nepel, M. Wang, B. Avula, I.A. Khan, Cytotoxic biomonitored study of 
Euphorbia umbellata (Pax) Bruyns. J. Ethnopharmacol. 183 (2016) 29-37. DOI:10.1016/j.jep.2016.02. 025.

24. A.P.G. Macabeo, W.S. Vidar, X. Chen, M. Decker, J. Heilmann, B. Wan, S.G. Franzblau, E.V. Galvez, M.A.M Aguinaldo, G.A. Cordell, Mycobacterium tuberculosis and cholinesterase inhibitors from Voacanga globosa. Eur. J. Med. Chem. 46(7) (2011) 3118 3123. DOI: 10.1016/j.ejmech.2011.04.025.

25. B.Y. Kim, S. Willbold, A. Kulik, S.E. Helaly, H. Zinecker, J. Wiese, J.F. Imhoff, M. Goodfellow, R.D. Süssmuth, H.P. Fiedler. Elaiomycins B and C, novel alkylhydrazides produced by Streptomyces sp. BK 190. J. Antibiotics 64(8) (2011) 595-597. DOI: 10.1038/ja.2011.53.

26. E.F. Pettersen, T.D. Goddard, C.C. Huang, G.S. Couch, D.M. Greenblatt, E.C. Meng, T.E. Ferrin, UCSF Chimera - A visualization system for exploratory research and analysis. J Comput Chem 25(13) (2004) 1605-1612. DOI:10.1002/jcc.20084.

27. J. Wang, W. Wang, P.A. Kollman, D.A. Case, Automatic atom type and bond type perception in molecular mechanical calculations. J. Mol. Graph. Model. 25(2) (2006) 247260. DOI:10.1016/j.jmgm.2005.12.005.

28. J. Yang, A. Roy, Y. Zhang, Protein-ligand binding site recognition using complementary binding-specific substructure comparison and sequence profile alignment. Bioinformatics 29(20) (2013) 2588-2595. DOI:10.1093/bioinformatics/btt447.

29. O. Trott, A.J. Olson, AutoDock Vina: Improving the speed and accuracy of docking with a new scoring function, efficient optimization, and multithreading. J. Comput. Chem. 31(2) (2010) 455-461. DOI:10.1002/jcc.21334. 
30. D.A. Case, T.E. Cheatham, T. Darden, H. Gohlke, R. Luo, K.M. Merz, A. Onufriev, C. Simmerling, B. Wang, R.J. Woods, The amber biomolecular simulation programs. J. Comput. Chem. 26(16) (2005) 1668-1688. DOI:10.1002/jcc.20290.

31. J. Wang, W. Wang, P.A. Kollman, D.A. Case, Antechamber: An accessory software package for molecular mechanical calculations. J. Am. Chem. Soc. 222 (2001) U403.

32. A. Toukmaji, C. Sagui, J. Board, T. Darden, Efficient particle-mesh Ewald-based approach to fixed and induced dipolar interactions. J. Chem. Phys. 113(24) (2000) 10913-10927. DOI:10.1063/1.1324708.

33. D.R. Roe, T.E. Cheatham, PTRAJ and CPPTRAJ: Software for processing and analysis of molecular dynamics trajectory data. J. Chem. Theory Comput. 9(7) (2013) 3084-3095. DOI:10.1021/ct400341p.

34. H. Sun, Y. Li, S. Tian, L. Xu, T. Hou, Assessing the performance of MM/PBSA and MM/GBSA methods. Accuracies of MM/PBSA and MM/GBSA methodologies evaluated by various simulation protocols using PDB bind data set. Phys. Chem. Chem. Phys. 16(31) (2014) 16719-16729. DOI:10.1039/c4cp01388c.

35. A. Khan, S. Saleem, M. Idrees, S.S. Ali, M. Junaid, A.C. Kaushik, D.Q. Wei, Allosteric ligands for the pharmacologically important Flavivirus target (NS5) from ZINC database based on pharmacophoric points, free energy calculations and dynamics correlation. J. Mol. Graph. Model. 82 (2018) 37-47. DOI:10.1016/j.jmgm.2018.03.004.

36. A. Khan, A.C. Kaushik, S.S. Ali, N. Ahmad, D.Q. Wei, Deep-learning-based target screening and similarity search for the predicted inhibitors of the pathways in Parkinson's disease. RSC Adv. 9(18) (2019) 10326-10339. DOI:10.1039/c9ra01007f. 
37. Y. Whang, A. Khan, A. Chandra Kaushik, M. Junaid, X. Zhang, D.Q. Wei, The systematic modeling studies and free energy calculations of the phenazine compounds as antituberculosis agents. J. Biomol. Struct. Dyn. 37(15) (2019) 4051-4069. DOI:10.1080/07391102.2018. 1537896.

38. M.J. Frisch, G.W. Trucks, H.B. Schlegel, G.E. Scuseria, M.A. Robb, J.R. Cheeseman, G. Scalmani et al., Gaussian16 (Revision A.03), Gaussian Inc. Wallingford CT, Gaussian16 (Revision A.03). (2016).

39. R.G. Parr, L. V. Szentpály, S. Liu, Electrophilicity index, J. Am. Chem. Soc. 121 (1999) 1922-1924. DOI:10.1021/ja983494x.

40. P.K. Chattaraj, S. Duley, L.R. Domingo, Understanding local electrophilicity/nucleophilicity activation through a single reactivity difference index, Org. Biomol. Chem. 10 (2012) 2855-2861. DOI:10.1039/c2ob06943a.

41. Lee, W. Yang, R.G. Parr, Development of the Colle-Salvetti correlation-energy formula into a functional of the electron density, Phys. Rev. B. 37 (1988) 785-789. DOI:10.1103/PhysRevB.37.785.

42. M.T.J. Quimque, K.I. Notarte, R.A.T. Fernandez, M.A.O. Mendoza, R.A.D. Liman, J.A.K. Lim, L.A.E. Pilapil, J.K.H. Ong, A.M. Pastrana, A. Khan, W. Dong-Qing, A.P. Macabeo, Virtual screening-driven drug discovery of SARS-CoV2 enzyme inhibitors targeting viral attachment, replication, post-translational modification and host immunity evasion infection mechanisms. J. Biomol. Struct. Dyn. (2020) 1-10. DOI:10.1080/07391102.2020.1776639. 
43. S. Awale, J.Y. Ueda, S. Athikomkulchai, S. Abdelhamed, S. Yokoyama, I. Saiki, R. Miyatake, Antiausterity agents from Uvaria dac and their preferential cytotoxic activity against human pancreatic cancer cell lines in a nutrient-deprived condition. J. Nat. Prod. 75(6) (2012) 1177-1183. DOI:10.1021/np300295h.

44. T. Kikuchi, M. Nihei, H. Nagai, H. Fukushi, K. Tabata, T. Suzuki, T. Akihisa, Albanol A from the root bark of Morus alba L. induces apoptotic cell death in HL60 human leukemia cell line. Chem. Pharm. Bull. 58(4) (2010) 568-571. DOI:10.1248/cpb.58.568

45. M. Ichimaru, N. Nakatani, M. Moriyasu, Y. Nishiyama, A. Kato, S.G. Mathenge, F.D. Juma, P.B. Chalo Mutiso, Hydroxyespintanol and schefflerichalcone: Two new compounds from Uvaria scheffleri. J. Nat. Med. 64(1) (2010) 75-79. DOI:10.1007/s11418-009-0358-0.

46. A. Vasas, I. Lajter, N. Kúsz, P. Forgó, G. Jakab, C. Fazakas, I. Wilhelm, I.A. Krizbai, J. Hohmann, Flavonoid, stilbene and diarylheptanoid constituents of Persicaria maculosa Gray and cytotoxic activity of the isolated compounds. Fitoterapia 145 (2020) 104610. DOI: $10.1016 /$ j.fitote.2020.104610.

47. Y.C. Wu, M. Sureshbabu, Y.C. Fang, Y.H. Wu, Y.H. Lan, F.R. Chang, Y.W. Chang, T.L. Hwang, Potent inhibition of human neutrophil activations by bractelactone, a novel chalcone from Fissistigma bracteolatum. Toxicol. Appl. Pharmacol. 266(3) (2013) 399407. DOI:10.1016/j.taap 2012.

48. B.E. Alexander, S. Sun, M.J. Palframan, G. Kociok-Köhn, D.F. Dibwe, S. Watanabe, L. Caggiano, S. Awale, S.E. Lewis, Sidechain diversification of grandifloracin allows identification of analogues with enhanced anti-austerity activity against human PANC-1 
pancreatic cancer cells. ChemMedChem 15(1) (2019) 125-135. DOI:10.1002/cmdc.201900549.

49. S. Matthew, L. Pan, Q. Shen, A.D. Kinghorn, S.M. Swanson, E.J. Carcache, Dichamanetin, a C-benzylated flavonoid from Piper sarmentosum inhibits cell growth and induces G1 cell cycle arrest in cancer cells through mitochondrial-mediated apoptosis. Cancer Res. (2017) 5349-5355. DOI:10.1158/1538-7445.AM2011-4229.

50. Y. Yong, S. Matthew, J. Wittwer, L. Pan, Q. Shen, A.D. Kinghorn, S.M. Swanson, E.J. de Blanco, Dichamanetin inhibits cancer cell growth by affecting ROS-related signaling components through mitochondrial-mediated apoptosis. Anticancer Res. 33(12) (2013) $5349-5355$.

51. K. Mahmood, S. Sablé, M. Païs, H.M. Ali, A. Hamid, A. Hadi, E. Guittet, Cyathoviridine, a cytotoxic metabolite from Cyathostemma viridiflorum. Nat. Prod. Lett. 3 (1993) 245249. DOI:10.3390/molecules 18066898.

52. A.T. Dinkova-Kostova, R. V. Kostov, P. Canning, Keap1, the cysteine-based mammalian intracellular sensor for electrophiles and oxidants, Arch. Biochem. Biophys. 617 (2017) 84-93. DOI:10.1016/j.abb.2016.08.005.

53. X. Li, D. Zhang, M. Hannink, L.J. Beamer, Crystal structure of the Kelch domain of human Keap1, J. Biol. Chem. (2004). DOI:10.1074/jbc.M410073200.

54. D.D. Zhang, M. Hannink, Distinct Cysteine Residues in Keap1 Are Required for Keap1Dependent Ubiquitination of Nrf2 and for Stabilization of Nrf2 by Chemopreventive Agents and Oxidative Stress, Mol. Cell. Biol. 23 (2003) 8137-8151. DOI:10.1128/mcb.23.22.8137-8151.2003. 
55. M. Uzzaman, M.K. Chowdhury, M. Belal Hossen, Thermochemical, Molecular docking and ADMET studies of Aspirin metabolites, Front. Drug, Chem. Clin. Res. 2 (2019). DOI:10.15761/fdccr.1000130.

56. J.A.H. Schwöbel, J.C. Madden, M.T.D. Cronin, Examination of Michael addition reactivity towards glutathione by transition-state calculations, SAR QSAR Environ. Res. 21 (2010) 693-710. DOI:10.1080/1062936X.2010.528943.

57. J.M. Henkin, Y. Ren, D.D. Soejarto, A.D. Kinghorn, The search for anticancer agents from tropical plants, Springer, Cham, (2018), pp 1-94. DOI:10.1007/978-3-319-93506-5_1.

58. T. Tsunoda, T. Ota, T. Fujimoto, K. Doi, Y. Tanaka, Y. Yoshida, M. Ogawa, H. Matsuzaki, M. Hamabashiri, D.R. Tyson, M. Kuroki M, Inhibition of phosphodiesterase-4 (PDE4) activity triggers luminal apoptosis and AKT dephosphorylation in a 3-D colonic-crypt model. Mol. Cancer, 11(1) (2012) 46-58. DOI:10.1186/1476-4598-11-46

59. K. Nishi, H. Luo, S. Ishikura, K. Doi, Y. Iwaihara, L. Wills, G.S. Baillie, T. Sakata, S. Shirasawa, T. Tsunoda, Apremilast induces apoptosis of human colorectal cancer cells with mutant KRAS. Anticancer Res. 37(7) (2017) 3833-3839. DOI:10.21873/anticanres.11762

60. J. Adams, R. Kelso, L. Cooley, The Kelch repeat superfamily of proteins: Propellers of cell function, Trends Cell Biol. (2000). DOI:10.1016/S0962-8924(99)01673-6.

61. P. Canning, F.J. Sorrell, A.N. Bullock, Structural basis of Keap1 interactions with Nrf2, Free Radic. Biol. Med. (2015). DOI:10.1016/j.freeradbiomed.2015.05.034.

62. S. Dayalan Naidu, A. Muramatsu, R. Saito, S. Asami, T. Honda, T. Hosoya, K. Itoh, M. Yamamoto, T. Suzuki, A.T. Dinkova-Kostova, C151 in KEAP1 is the main cysteine sensor for the cyanoenone class of NRF2 activators, irrespective of molecular size or shape, Sci. Rep. (2018). DOI:10.1038/s41598-018-26269-9. 
63. G. Rachakonda, Y. Xiong, K.R. Sekhar, S.L. Stamer, D.C. Liebler, M.L. Freeman, Covalent modification at Cys151 dissociates the electrophile sensor Keap1 from the ubiquitin ligase CUL3, Chem. Res. Toxicol. 21 (2008) 705-710. DOI:10.1021/tx700302s.

64. D.E. Stack, G. Li, A. Hill, N. Hoffman, Mechanistic insights into the Michael addition of deoxyguanosine to catechol estrogen-3,4-quinones, Chem. Res. Toxicol. 21 (2008) 14151425. $10.1021 / \mathrm{tx} 800071 \mathrm{u}$.

65. T. Ginex, M. Trius, F.J. Luque, Computational Study of the Aza-Michael Addition of the Flavonoid (+)-Taxifolin in the Inhibition of $\beta$-Amyloid Fibril Aggregation, Chem. - A Eur. J. 24 (2018) 5813-5824. DOI:10.1002/chem.201706072. 